\title{
Experimental Investigation of Masonry Infilled R/C Frames
}

\author{
K.C. Stylianidis* \\ Department of Civil Engineering, Aristotle University, Thessaloniki, Greece
}

\begin{abstract}
Although it is well documented that infills significantly affect the dynamic characteristics and the seismic response of the bare basic structural system, codes are reluctant to encourage consideration of infills as main structural elements, mainly due to structural uncertainties and computational complexities. Part of the uncertainties are due to the very many parameters affecting the behavior of the system, such as infill materials, reinforcing of infills, connection to the surrounding frame, geometry, relative stiffness and strength, local construction techniques etc. In the present paper three successive experimental programs, conducted at the R/C and Masonry Structures Laboratory of the Aristotle University, are described, commented and discussed. All of them refer to single-storey one-bay 1:3 scale R/C moment resisting frames. The first program consisted of 18 specimens, 2 bare and 16 unreinforced masonry (URM) infilled. The second program was an extension and a supplement of the previous one. It consisted of 20 more specimens, 6 bare and 14 URM infilled. The third program was directed towards the investigation of quick and low cost strengthening methods of R/C frames damaged by earthquakes, using several infill techniques. For this purpose 10 of the damaged specimens of the first program were repaired and strengthened.
\end{abstract}

Keywords: Ductility, energy dissipation capacity, experimental results, masonry infill walls, stiffness, strength, strengthening techniques.

\section{INTRODUCTION}

The significant change of the static and dynamic characteristics of the bare basic structural system by the incorporation of infills is a fact stated by many authors and experienced in every day praxis. Older versions of codes [1, 2] provide specific instructions for the design and construction of infilled structures, recommending two alternatives: either an effective isolation of the infills from the surrounding frames, so that their structural effects can correctly be neglected, or a tight placing of the infills so that their interaction with the frames should be properly considered in the design, detailing and construction, especially for seismic excitations.

In the first case of the isolation of the infills, the structural system is clear and relatively reliable but, as separation at the bottom of the infill and adequate resistance to out of plane seismic loads are difficult to achieve, this can be hazardous [3]. Furthermore, the infills add a significant undesirable mass. In the second case of the tight placing of the infills, the increased strength, stiffness and energy dissipation capacity seem to improve the seismic behavior of the regular buildings although base shear may be increased because of the increase of stiffness [4]. Recent codes [5] give special attention to the consequences of irregularities in plan and in elevation produced by the infills, which should be taken into account.

Although experimental data have been enriched over the last decades and analytical methods have been significantly improved, a reliable consideration of the interaction between

*Address correspondence to this author at the Department of Civil Engineering, Aristotle University of Thessaloniki, PO BOX 482, 54124, Greece; Tel: +30 2310995803; Fax: +30 2310995614; E-mail: kcstyl@ civil.auth.gr the infills and the surrounding frames strikes against the structural uncertainties and computational complexities. In fact, even in the case of an extensively studied local partitioning type, structural uncertainties due to quality of the workmanship, local weaknesses because of embedded installations, removal of partitions to other places during the life time of the building, initial gaps between the infill and the surrounding frame etc. can considerably influence the behavior of the structure. In addition, analytical models of the infill presented so far, the diagonal strut being the most familiar, have some disadvantages, such as the underestimation of the rotational degree of freedom of the infill [6] appearing at high distortions around an axis perpendicular to its plane, the difficulty to model reliably the descending branch of the envelope after failure of the infill, the degradation of the infill due to cyclic loading, the difficulty in taking into account the influence of the mode of failure of both the infill and the frame, mainly the brittle out of plain probable failure of the infill.

On the other hand, in spite of the fact that experimental studies have been carried out in almost all over the world [7$10]$, different materials, construction techniques and test procedures do not permit, for the time being, the formulation of a valid and reliable general purpose analytical model, representing the behavior of the infill. In this perspective, experimental results are always welcome, enriching the data and supporting the improvement of the existing analytical models.

In the present paper three successive experimental programs, conducted at the Lab of R/C and Masonry Structures, Department of Civil Engineering, Aristotle University of Thessaloniki, are described, commented and discussed. All of them refer to single-storey one-bay 1:3 scale R/C moment resisting frames [11-13]. 


\section{METHODOLOGY}

\subsection{Geometry of the Models and Materials}

The experimental models consisted of a series of singlestorey one-bay 1:3 scale R/C ductile frames. The design and detailing of the R/C frames are shown in Figs. (1 and $\mathbf{2}$ ) and in Table 1. The mechanical properties of the materials used, determined from tests on units or subassemblages, are shown in Table 2. It must be mentioned that scaling problems did not permit a complete simulation of the materials usually used in Greece. So, the high strength deformed bars, which are the rule for the construction practice, were replaced by relatively low strength plain bars, welded to each other in the region of joints. Taking into account the scaling ratio, the horizontally perforated clay brick units Fig. (2) used in the project, were relatively big compared to the units usually used in Greece.

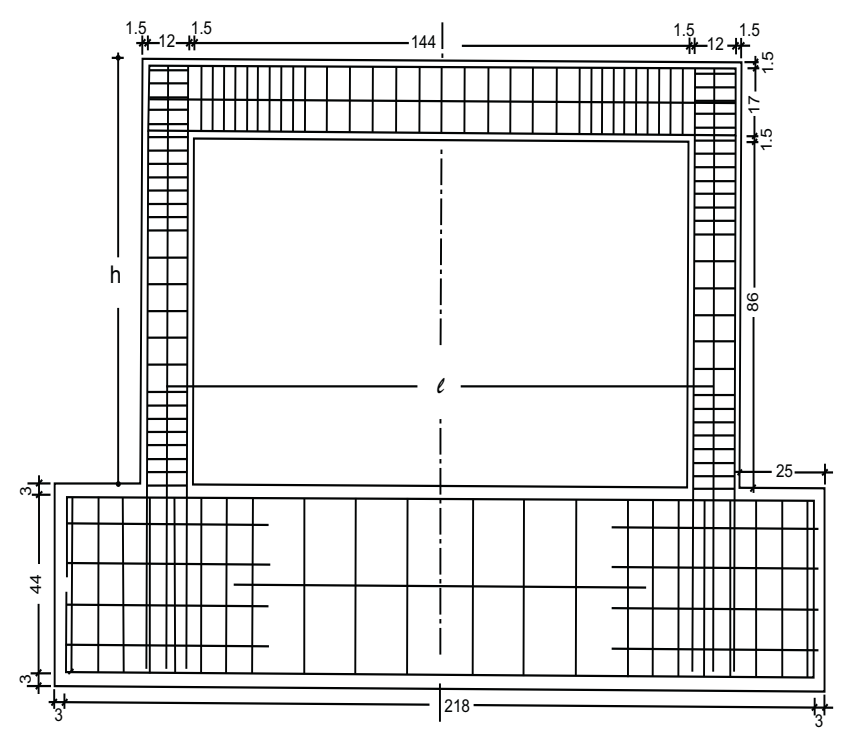

Fig. (1). Geometry and reinforcement layout of the bare and infilled frames (a typical frame with $1 / \mathrm{h}=1.5$ is shown here).

\section{Table 1. Design Characteristics of R/C Frames}

\begin{tabular}{|c|c|c|c|}
\hline \multicolumn{2}{|c|}{ Design characteristics } & \multirow{3}{*}{$\begin{array}{c}\text { Prototype } \\
477 \\
318\end{array}$} & \multirow{3}{*}{$\begin{array}{c}1: 3 \text { - model } \\
159 \\
106\end{array}$} \\
\hline Length $(\mathrm{cm})-$ axis to axis & $1 / \mathrm{h}=1.5$ & & \\
\hline of the columns & $1 / \mathrm{h}=1.0$ & & \\
\hline \multicolumn{2}{|l|}{ Height $(\mathrm{cm})$} & 318 & 106 \\
\hline \multicolumn{2}{|c|}{ Cross section of the columns $(\mathrm{cm})$} & $45 \times 45$ & $15 \times 15$ \\
\hline \multicolumn{2}{|c|}{ Cross section of the beam $(\mathrm{cm})$} & $30 \times 60$ & $10 \times 20$ \\
\hline \multirow{2}{*}{$\begin{array}{l}\text { Longitudinal reinfor- } \\
\text { cement of the columns }\end{array}$} & $1.01 \%$ & $8 ø 18$ & $8 ø 6$ \\
\hline & $1.79 \%$ & $8 ø 24$ & $8 ø 8$ \\
\hline \multirow{2}{*}{$\begin{array}{l}\text { Tensile and compression } \\
\text { reinforcement of the beam }\end{array}$} & $0.42 \%$ & $3 \varnothing 18$ & $3 \varnothing 6$ \\
\hline & $0.75 \%$ & $3 \varnothing 24$ & $3 \varnothing 8$ \\
\hline \multicolumn{2}{|l|}{ Stirrups } & $\varnothing 8$ & $\varnothing 2.7$ \\
\hline \multicolumn{2}{|c|}{$\begin{array}{l}\text { Spacing of stirrups in critical regions } \\
(\mathrm{cm})\end{array}$} & 10 & 3.33 \\
\hline \multicolumn{2}{|c|}{$\begin{array}{l}\text { Spacing of stirrups in non-critical re- } \\
\text { gions }(\mathrm{cm})\end{array}$} & 20 & 6.67 \\
\hline
\end{tabular}
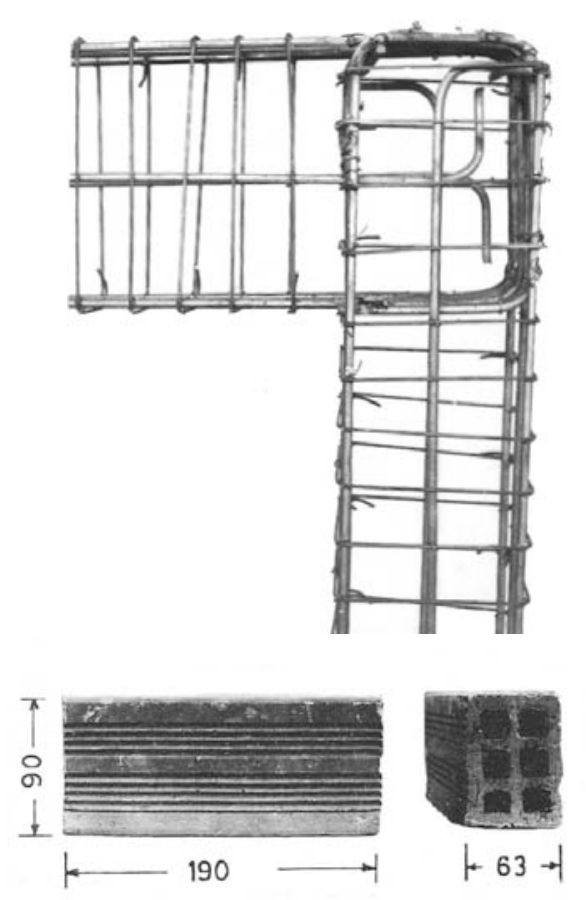

Fig. (2). Joint detailing of an R/C model and perforated clay brick units used in the project (dimensions in $\mathrm{mm}$ ).

To avoid the influence of the scatter of the workmanship quality, mainly the gaps between the beam and the infill, both the frames and the infills were constructed in horizontal beds Fig. (3). It must also be mentioned that the axial loads on the columns were imposed after the infills were constructed. This is a violation of the actual construction technique where a significant portion of the axial load on the columns is due to self weight of the R/C structural system and is imposed before the construction of the infills.

\subsection{Test Set-up and Procedure}

Lateral loading was applied by two single acting hydraulic jacks at the level of the axis of the R/C beam Figs. ( 4 and 5). The loading program included full reversals of gradually increasing displacements. Two reversals were applied for each displacement level Fig. (6) that correspond to two cycles of imposed displacements per level and two respective loops of response. The experimental procedure was terminated when the angular distortion reached the value of about $3 \%$ for each frame. The appearance and propagation of cracking was also recorded for both the frame and the infill throughout each test. The main final output of the experiments was one load - displacement curve for each specimen. The assessment of the behavior of the frames was performed on the basis of strength, initial stiffness, energy dissipation and ductility.

\section{EXPERIMENTAL RESULTS}

\subsection{Program \#1}

The first program consisted of 18 specimens, 2 bare and 16 URM infilled [14]. While the R/C frames and the thickness of the infill remained constant for all the models (columns $15 \times 15 \mathrm{~cm}$, beam $10 \times 20 \mathrm{~cm}$, aspect ratio of the frame 
Table 2. Mechanical Properties of the Materials Used (MPa) - Programs \#1 and \#2

\begin{tabular}{|c|c|c|c|}
\hline Material & Compressive strength & Shear strength & $\begin{array}{l}\text { Ratio of shear to compres- } \\
\text { sive strength }\end{array}$ \\
\hline Concrete (program \#1) & 26.5 & & \\
\hline Concrete (program \#2) & 27.9 & & \\
\hline Brick units $(\mathrm{b}=6.3 \mathrm{~cm})$ & 6.0 & & \\
\hline Brick units $(\mathrm{b}=9.0 \mathrm{~cm})$ & 5.6 & & \\
\hline Mortar (type S - ASTM) & 10.7 & & \\
\hline Masonry (type $\mathrm{S}$ mortar) $6.3 \mathrm{~cm}$ thick & 4.2 & 0.33 & 0.08 \\
\hline Masonry (type S mortar) $9.0 \mathrm{~cm}$ thick & Not used & & \\
\hline Mortar (type O - ASTM) & 4.0 & & \\
\hline Masonry (type $\mathrm{O}$ mortar) $6.3 \mathrm{~cm}$ thick & 2.3 & 0.26 & 0.11 \\
\hline Masonry (type $\mathrm{O}$ mortar) $9.0 \mathrm{~cm}$ thick & 1.9 & & \\
\hline \multicolumn{2}{|c|}{ Steel bars } & Yield stress & Ultimate stress \\
\hline \multicolumn{2}{|c|}{$\varnothing 8$} & 340 & 467 \\
\hline \multicolumn{2}{|c|}{$\varnothing 6$} & 348 & 457 \\
\hline \multicolumn{2}{|c|}{$\varnothing 2.7$} & 271 & 395 \\
\hline
\end{tabular}
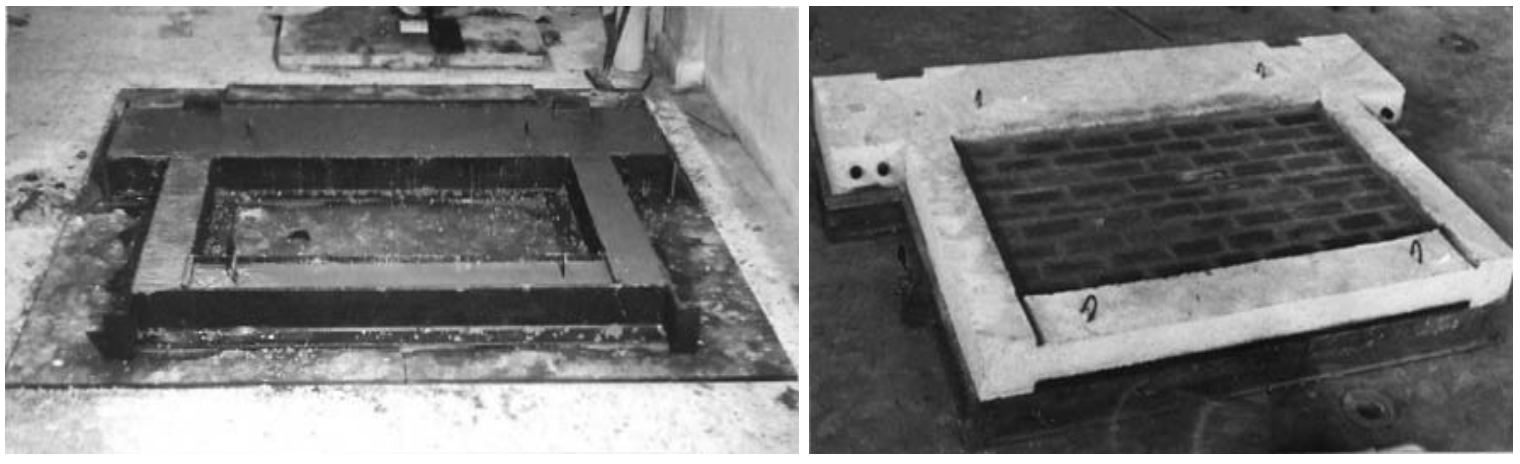

Fig. (3). Horizontal bed used to construct the R/C frames and to build the masonry infill.

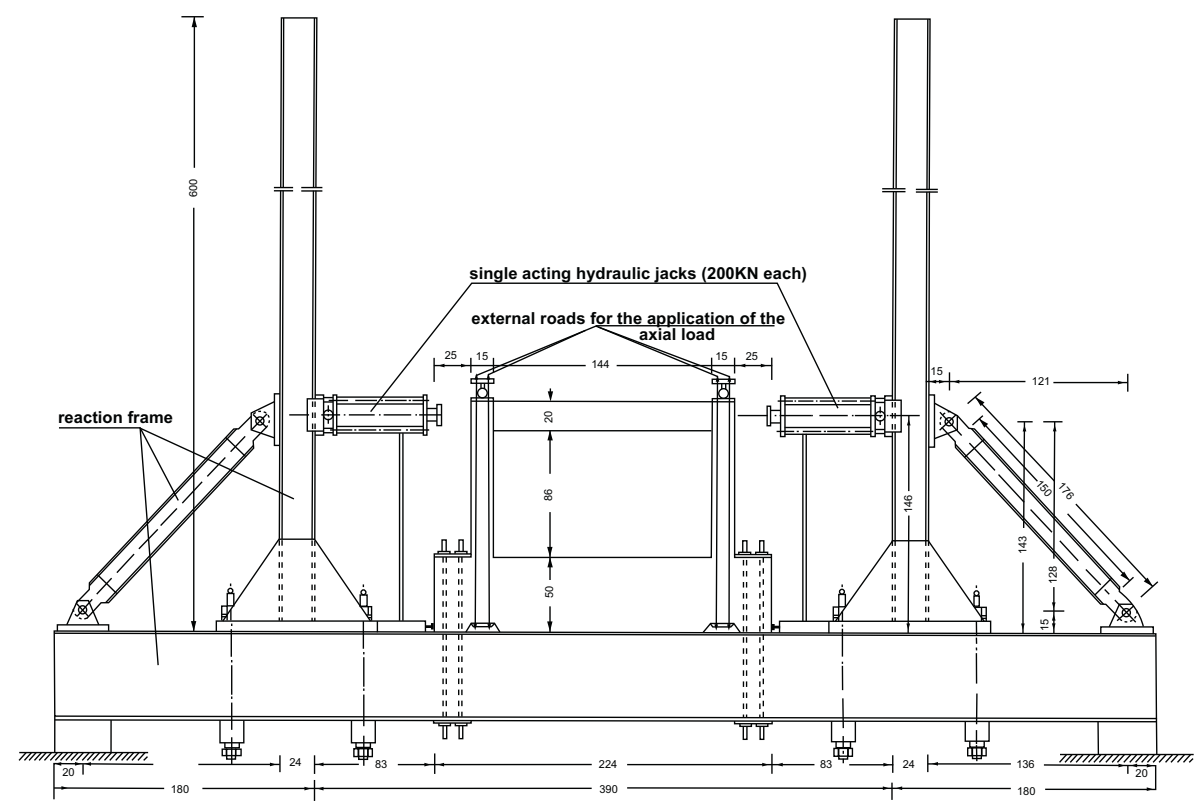

Fig. (4). Test set-up (dimensions in $\mathrm{mm}$ ). 


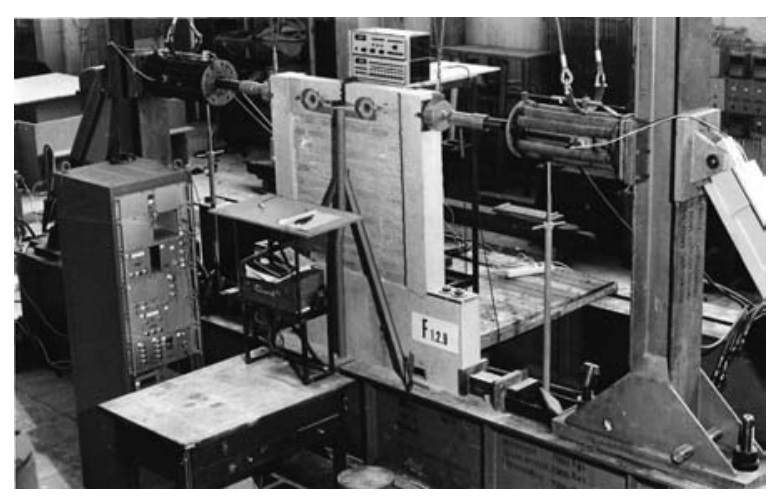

Fig. (5). General view of test set-up and instrumentation.

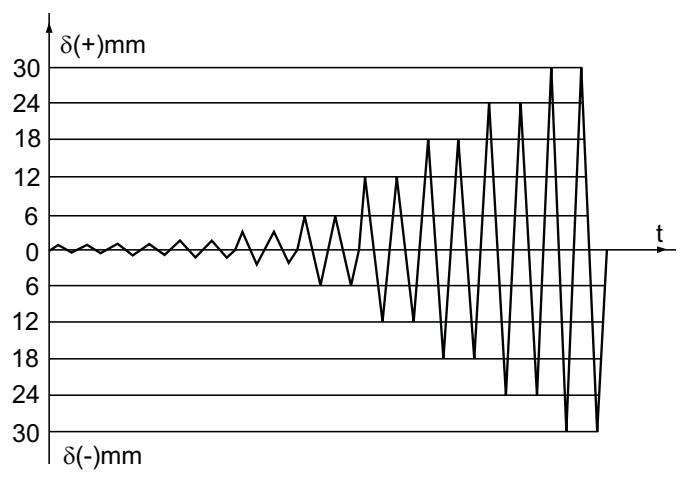

Fig. (6). Loading program.

- The level of the axial compressive load on the columns. Two levels were selected, one of zero and another of $14 \%$ of the ultimate strength of the columns.

- The contact conditions of the infill against the internal surface of the frame. Half of the models had a surround- ing mortar joint against the frame representing good continuity conditions, while the other half had a $1 \mathrm{~mm}$ wide gap between the infill and the upper beam, representing defecting continuity condition.

- The quality of the mortar. Two mortar types were used, one strong and one week (types $\mathrm{S}$ and $\mathrm{O}-\mathrm{ASTM}$ respectively).

- The presence of a concrete lintel beam. Half of the infills had a slightly reinforced concrete beam at the midheight of the infill, not connected to the surrounding frame, while the other half had no lintel beam.

The main observational remarks on the behavior of bare and infilled frames are the following:

- The failure modes of the infilled frames are almost the same as those of the corresponding bare frames. Typically, plastic hinges occurred at the bottom and the top of the columns Figs. (7 and 8) in frames without axial force. On the contrary, in frames with axial load, the plastic hinges occurred at the bottom of the columns and the ends of the beams. In some cases, plastic hinges occurred at the midheight of the columns, when slip failure of the infill occurred across a horizontal mortar joint.

- The hysteretic loops of the bare frames are rich, typical to the inelastic rotation of the plastic hinges Fig. (9). On the contrary, pinching effects occur at the infilled frames, typical of brittle behavior due to infill cracking Fig. (10).

$1: \mathrm{h}=159 / 106=1.5$, calculated from axis to axis distances of columns and beams Fig. (1), reinforcement ratio of columns and beam $1.0 \%$, infill thickness $6.3 \mathrm{~cm}$ ) the influence of the following parameters was investigated Table $\mathbf{3}$.

Table 3. Nomenclature of the Frame Models - Program \#1

\begin{tabular}{|c|c|c|c|c|c|c|c|c|}
\hline \multirow{2}{*}{ Name } & \multicolumn{2}{|c|}{ Mortar type } & \multicolumn{2}{|c|}{ Lintel beam } & \multicolumn{2}{|c|}{ Contact conditions } & \multicolumn{2}{|c|}{ Axial force } \\
\hline & $\mathrm{S}$ & $\mathrm{O}$ & no & yes & good & bad & no & yes \\
\hline FB & \multicolumn{6}{|c|}{ Bare frame } & $\bullet$ & \\
\hline F1 & $\bullet$ & & $\bullet$ & & $\bullet$ & & $\bullet$ & \\
\hline $\mathrm{F} 2$ & & $\bullet$ & $\bullet$ & & - & & $\bullet$ & \\
\hline F3 & $\bullet$ & & & $\bullet$ & - & & $\bullet$ & \\
\hline $\mathrm{F} 4$ & & $\bullet$ & & $\bullet$ & - & & - & \\
\hline F5 & $\bullet$ & & $\bullet$ & & & $\bullet$ & $\bullet$ & \\
\hline F6 & & $\bullet$ & - & & & - & • & \\
\hline F7 & $\bullet$ & & & $\bullet$ & & $\bullet$ & $\bullet$ & \\
\hline F8 & & $\bullet$ & & $\bullet$ & & $\bullet$ & $\bullet$ & \\
\hline FBN & \multicolumn{6}{|c|}{ Bare frame } & & $\bullet$ \\
\hline $\mathrm{F} 1 \mathrm{~N}$ & $\bullet$ & & $\bullet$ & & $\bullet$ & & & - \\
\hline $\mathrm{F} 2 \mathrm{~N}$ & & $\bullet$ & $\bullet$ & & $\bullet$ & & & $\bullet$ \\
\hline F3N & - & & & $\bullet$ & $\bullet$ & & & $\bullet$ \\
\hline F4N & & $\bullet$ & & $\bullet$ & $\bullet$ & & & $\bullet$ \\
\hline F5N & $\bullet$ & & - & & & - & & $\bullet$ \\
\hline F6N & & $\bullet$ & $\bullet$ & & & $\bullet$ & & $\bullet$ \\
\hline F7N & $\bullet$ & & & $\bullet$ & & $\bullet$ & & $\bullet$ \\
\hline $\mathrm{F} 8 \mathrm{~N}$ & & $\bullet$ & & $\bullet$ & & $\bullet$ & & $\bullet$ \\
\hline
\end{tabular}




\subsection{Program \#2}

The second program was an extension and a supplement of the previous one. It consisted of 20 more specimens, 6 bare and 14 URM infilled [15]. While the dimensions of beam and column sections remained constant, the mortar quality was constantly of type O - ASTM, there was no gap between the infill and the upper beam and no lintel at the midheight of the infill, the program incorporated the most significant parameters of the previous program and some new ones Table 4.

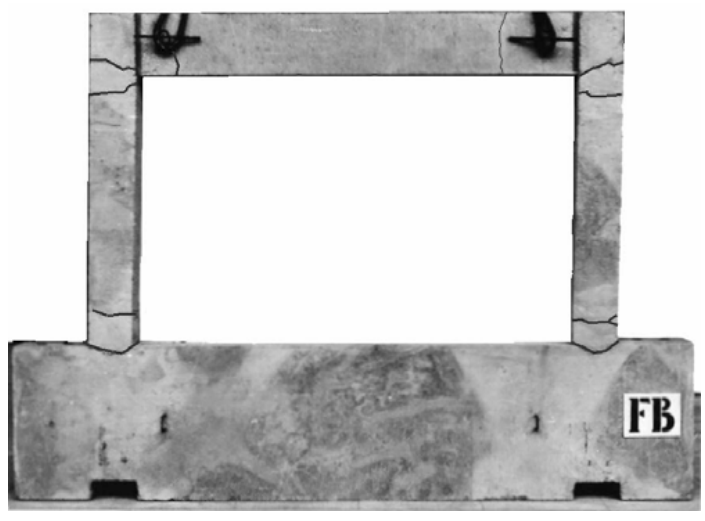

Fig. (7). Failure mode of the bare frame FB.

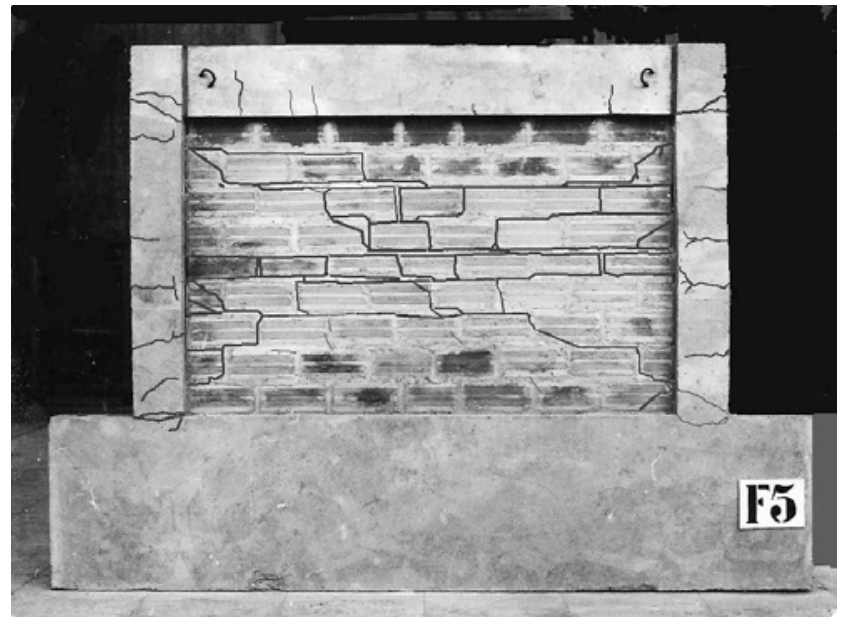

Fig. (8). Failure mode of the infilled frame F5.

- Again, the level of the axial compressive load on the columns. The same levels were selected, one of zero and another of $14 \%$ of the ultimate strength of the columns.

- The aspect ratio of the frame 1:h. Two values were selected, one equal to 1.0 and another equal to 1.5 .

- The reinforcement ratio of the columns and beam. Again two values were selected, one equal to $1.0 \%$ and another

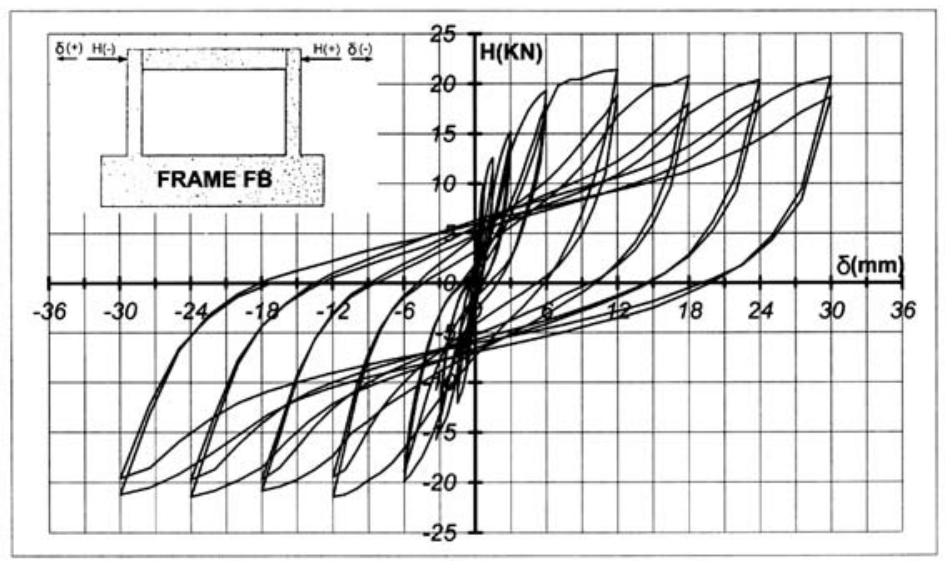

Fig. (9). Lateral load - displacement loops. Bare frame FB.

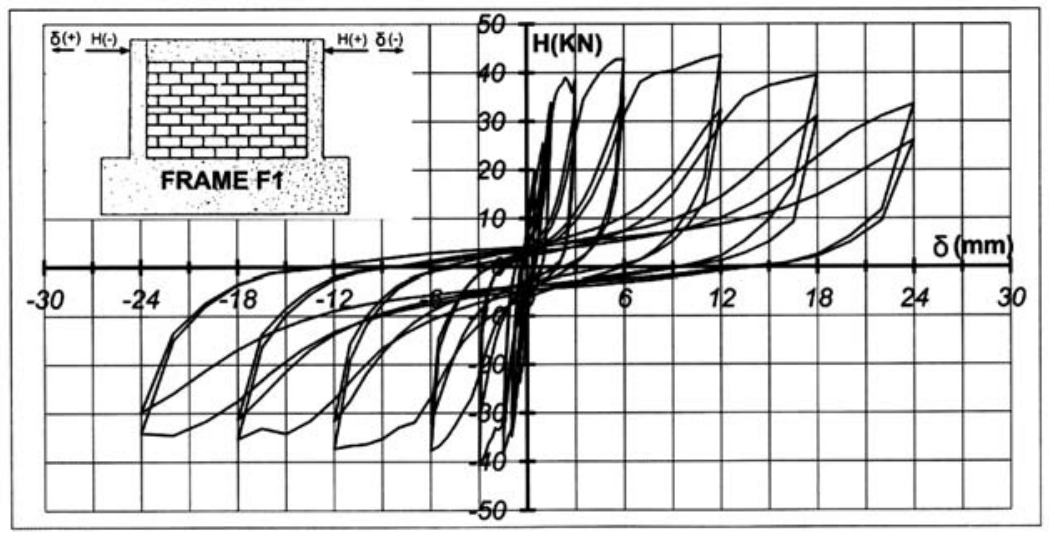

Fig. (10). Lateral load - displacement loops. Infilled frame F1. 
Table 4. Nomenclature of the Frame Models - Program \#2

\begin{tabular}{|c|c|c|c|c|c|c|c|c|}
\hline \multirow{2}{*}{ Name } & \multicolumn{2}{|c|}{ Aspect ratio } & \multicolumn{2}{|c|}{ Reinforcement ratio (\%) } & \multicolumn{2}{|c|}{ Infill thickness (cm) } & \multicolumn{2}{|c|}{ Axial force } \\
\hline & 1.5 & 1.0 & 1.0 & 1.8 & 6.3 & 9.0 & no & yes \\
\hline$* \mathrm{FB}_{1.5,1,-}$ & $\bullet$ & & $\bullet$ & & \multicolumn{2}{|c|}{ Bare frame } & $\bullet$ & \\
\hline $\mathrm{FB}_{1,1,-}$ & & $\bullet$ & $\bullet$ & & \multicolumn{2}{|c|}{ Bare frame } & $\bullet$ & \\
\hline $\mathrm{FB}_{1.5,2,-}$ & $\bullet$ & & & $\bullet$ & \multicolumn{2}{|c|}{ Bare frame } & $\bullet$ & \\
\hline $\mathrm{FB}_{1,2,-}$ & & $\bullet$ & & $\bullet$ & \multicolumn{2}{|c|}{ Bare frame } & $\bullet$ & \\
\hline$* \mathrm{~F}_{1.5,1,6}$ & $\bullet$ & & $\bullet$ & & $\bullet$ & & $\bullet$ & \\
\hline $\mathrm{F}_{1,1,6}$ & & $\bullet$ & $\bullet$ & & $\bullet$ & & $\bullet$ & \\
\hline $\mathrm{F}_{1.5,2,6}$ & $\bullet$ & & & $\bullet$ & $\bullet$ & & $\bullet$ & \\
\hline $\mathrm{F}_{1,2,6}$ & & $\bullet$ & & $\bullet$ & $\bullet$ & & $\bullet$ & \\
\hline $\mathrm{F}_{1.5,1,9}$ & $\bullet$ & & $\bullet$ & & & $\bullet$ & $\bullet$ & \\
\hline $\mathrm{F}_{1,1,9}$ & & $\bullet$ & $\bullet$ & & & $\bullet$ & $\bullet$ & \\
\hline $\mathrm{F}_{1.5,2,9}$ & $\bullet$ & & & $\bullet$ & & $\bullet$ & $\bullet$ & \\
\hline $\mathrm{F}_{1,2,9}$ & & $\bullet$ & & $\bullet$ & & $\bullet$ & $\bullet$ & \\
\hline$* \mathrm{FBN}_{1.5,1,-}$ & $\bullet$ & & $\bullet$ & & \multicolumn{2}{|c|}{ Bare frame } & & $\bullet$ \\
\hline $\mathrm{FBN}_{1,1,-}$ & & $\bullet$ & $\bullet$ & & \multicolumn{2}{|c|}{ Bare frame } & & $\bullet$ \\
\hline $\mathrm{FBN}_{1.5,2,-}$ & $\bullet$ & & & $\bullet$ & \multicolumn{2}{|c|}{ Bare frame } & & $\bullet$ \\
\hline $\mathrm{FBN}_{1,2,-}$ & & $\bullet$ & & $\bullet$ & \multicolumn{2}{|c|}{ Bare frame } & & $\bullet$ \\
\hline$* \mathrm{FN}_{1.5,1,6}$ & $\bullet$ & & $\bullet$ & & $\bullet$ & & & $\bullet$ \\
\hline $\mathrm{FN}_{1,1,6}$ & & $\bullet$ & $\bullet$ & & $\bullet$ & & & $\bullet$ \\
\hline $\mathrm{FN}_{1.5,2,6}$ & $\bullet$ & & & $\bullet$ & $\bullet$ & & & $\bullet$ \\
\hline $\mathrm{FN}_{1,2,6}$ & & $\bullet$ & & $\bullet$ & $\bullet$ & & & $\bullet$ \\
\hline $\mathrm{FN}_{1.5,1,9}$ & $\bullet$ & & $\bullet$ & & & $\bullet$ & & $\bullet$ \\
\hline $\mathrm{FN}_{1,1,9}$ & & $\bullet$ & $\bullet$ & & & $\bullet$ & & $\bullet$ \\
\hline $\mathrm{FN}_{1.5,2,9}$ & $\bullet$ & & & $\bullet$ & & $\bullet$ & & $\bullet$ \\
\hline $\mathrm{FN}_{1,2,9}$ & & $\bullet$ & & $\bullet$ & & $\bullet$ & & • \\
\hline
\end{tabular}

equal to $1.8 \%$.

- The thickness of the masonry infill. Two values were selected again, one equal to $6.3 \mathrm{~cm}$ and another equal to $9.0 \mathrm{~cm}$.

To complete the data of all parameters, four frame models of the previous program were used. As a result, 24 models were used to evaluate the influence of the selected parameters.

The main observational remarks on the behavior of bare and infilled frames are the following:

- As far as bare frames are concerned, no brittle failure due to shear of columns and beam was observed. The first pair of plastic hinges was formed at the bottom of the columns. In the frames with no external axial load on the columns, the second pair was formed at the top of the columns. In the frames with an axial load, the second pair was formed alternatively at the top of the columns or at the ends of the beam, depending on the longitudinal reinforcement ratio Figs. (11 and 12). The failure modes ob- served were found to be in good agreement to the plastic analysis carried out and to the findings of the first program.

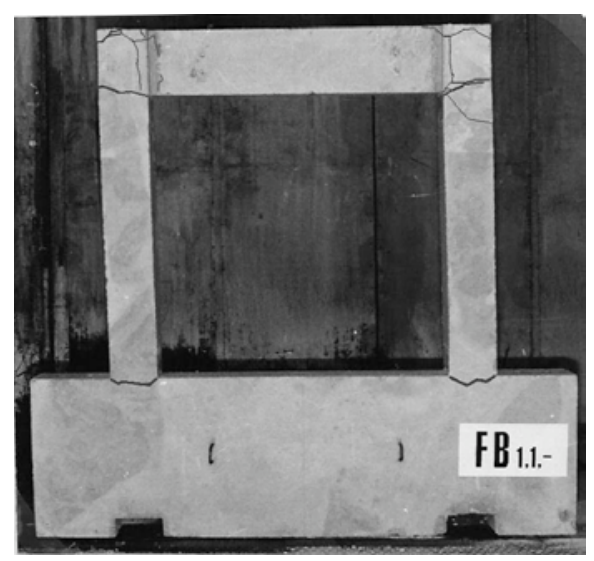

Fig. (11). Failure modes of bare frame $\mathrm{FB}_{1,1,-,}$ without axial load on the columns. 
Table 5. Mechanical Properties of the Materials Used (MPa) - Program \#3

\begin{tabular}{|c|c|c|c|}
\hline Material & Compressive strength & Shear strength & $\begin{array}{l}\text { Ratio of shear to compres- } \\
\text { sive strength }\end{array}$ \\
\hline Concrete & 25.5 & & \\
\hline Brick units $(b=6.3 \mathrm{~cm})$ & 6.0 & & \\
\hline Mortar (type O - ASTM) & 3.4 & & \\
\hline Mortar jacket & 11.7 & & \\
\hline Masonry (type $\mathrm{O}$ mortar) $6.3 \mathrm{~cm}$ thick, no jacket & 2.3 & 0.26 & 0.11 \\
\hline $\begin{array}{l}\text { Masonry (type } \mathrm{O} \text { mortar), } 8.3 \mathrm{~cm} \text { thick, reinforced mortar jackets } \\
1 \mathrm{~cm} \text { thick in both sides, no transverse connection }\end{array}$ & 2.2 & 0.94 & 0.43 \\
\hline $\begin{array}{l}\text { Masonry (type } \mathrm{O} \text { mortar), } 8.3 \mathrm{~cm} \text { thick, reinforced mortar jackets } \\
1 \mathrm{~cm} \text { thick in both sides, transverse connection }\end{array}$ & 3.0 & 1.12 & 0.37 \\
\hline \multicolumn{2}{|l|}{ Steel bars } & Yield stress & Ultimate stress \\
\hline \multicolumn{2}{|l|}{$\varnothing 6$} & 348 & 457 \\
\hline \multicolumn{2}{|l|}{$\varnothing 2.7$} & 271 & 395 \\
\hline
\end{tabular}

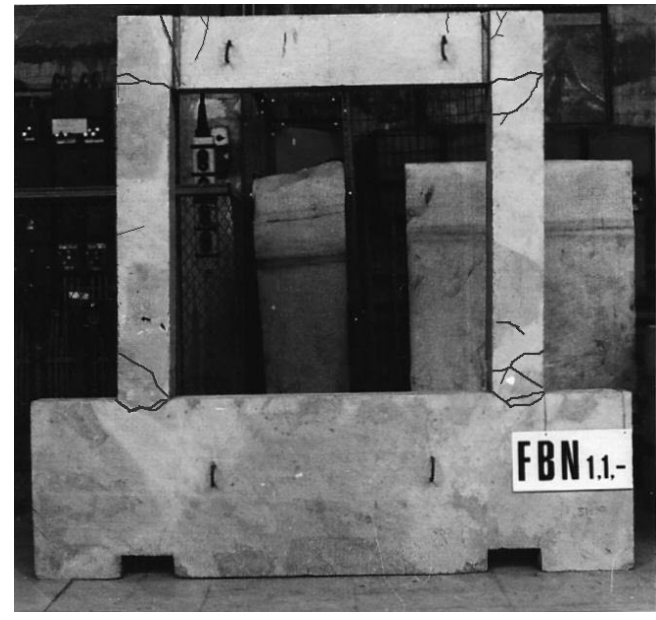

Fig. (12). Failure modes of bare frame $\mathrm{FBN}_{1,1,-,}$ with axial load on the columns.

- Concerning the infilled frames, a separation of the infills from the surrounding frame at the non-loaded corners occurred at relatively low displacements. At higher displacements, a combined failure mode of the infill was observed, due to diagonal tension and sliding shear cracking across a horizontal mortar joint close to the midheight of the infill. In the frames having an external axial load on the columns, in some cases a transverse splitting of brick units was observed Fig. (13). Concerning the $\mathrm{R} / \mathrm{C}$ frames, the mode of failure was the same as the mode of bare frames. Although sliding shear failure of the infills is reported by many authors $[3,16]$ to lead to shear failure of the R/C columns, in the case of the present program some diagonal cracks occurred but shear failure of the columns was not observed, probably because the infill was weak in relation to the $\mathrm{R} / \mathrm{C}$ frames. It must also be mentioned that in the infilled frames with no external load on the columns, the loss of contact of the infill to the frame was very rapid, probably due to the elongation of the columns under tension. On the contrary, in the infilled frames with an external axial load on the columns, the loss of contact was very slow.

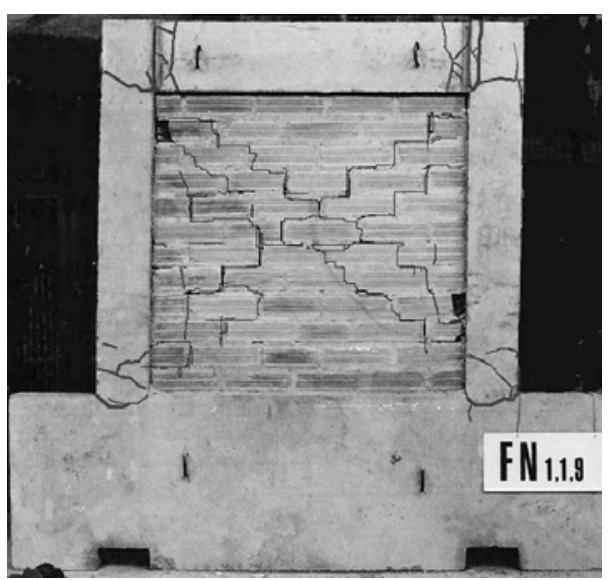

Fig. (13). Failure mode of infilled frame, transverse splitting of some brick units is obvious.

- As in the first program, the hysteretic loops of the bare frames are rich, typical of the inelastic rotation of the plastic hinges Fig. (14). On the contrary, pinching effects occur at the infilled frames, typical to brittle behavior due to infill cracking Fig. (15). The differences in the hysteretic behavior between the bare and the infilled frames are more obvious in the models without axial load on the columns.

\subsection{Program \#3}

The third program was directed towards the investigation of quick and low cost strengthening methods of $\mathrm{R} / \mathrm{C}$ frames damaged by earthquakes, using several infill techniques. The materials used are described in Table 5. Same bricks and mortar, as in programs \#1 and \#2 were used see also Table 2. The wallets used Fig. (16) were one brick long $(19.0 \mathrm{~cm})$, one brick wide $(6.3 \mathrm{~cm})$ and four bricks high $(40.0 \mathrm{~cm})$.

It is worth mentioning that the compressive strength of masonry wallets, strengthened by a $1 \mathrm{~cm}$ reinforced mortar jacket on both sides of the infill, was not improved in relation to the wallets without strengthening. This is due to the fact that the failure mode of both the wallets is the same, 


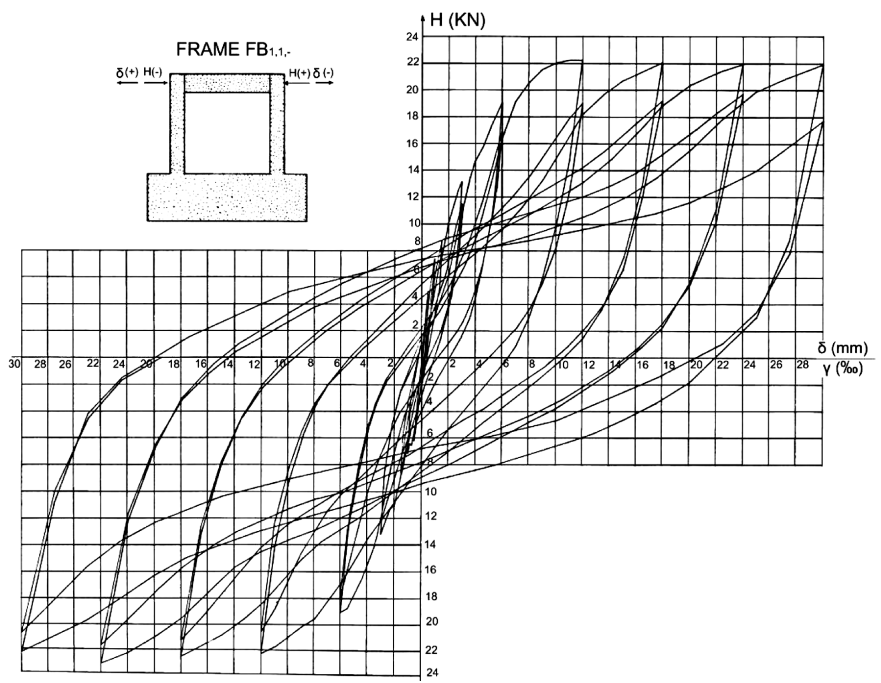

Fig. (14). Lateral load - displacement loops. Bare frame $F_{1,1,-}$.

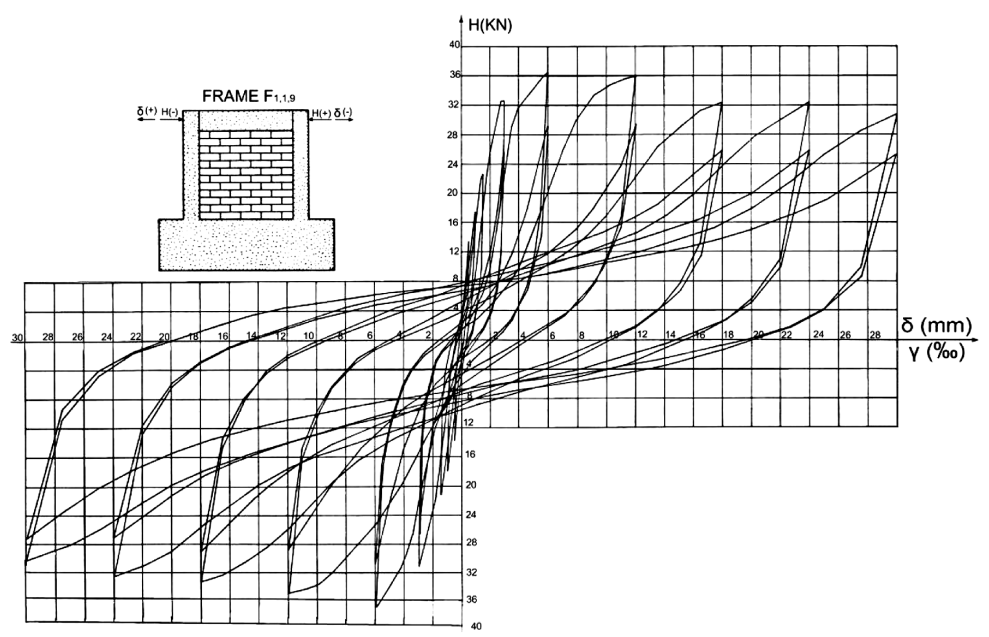

Fig. (15). Lateral load - displacement loops. Infilled frame $F_{1,1,9}$.

namely transverse splitting (Fig. 16, Specimen A3), not affected by the strengthening technique. On the contrary, the improvement of the compressive strength of the wallets in which the reinforcement of the infills was transversely connected was more than $40 \%$. The failure mode of these wallets was practically the same, but the contribution of the transverse reinforcement improved the strength and the ductility characteristics of the infill (Fig. 16, Specimen B3). Concerning shear strength, determined by diagonal test, the relatively strong mortar added much to the infill. Note from Table 5 that the ratio of shear to compressive strength grew from about 0.10 for the infills without mortar to about 0.40 for the infills with the mortar. This is a critical issue on the failure modes of the infilled frames, as it will be explained below.

To study the contribution of several techniques, 10 of the damaged specimens of the first program were repaired and strengthened as follows Table 6.

- After removing permanent distortions of the frame and infill remainings, cracks at beam and columns were simply repaired by epoxy resins. No further R/C strengthening measures were applied.
- A pair of frames was left bare, one frame with zero axial force and another one with an axial force equal to $14 \%$ of the ultimate strength of the columns, as in the first and the second program.

- A second pair was strengthened by a new URM infill.

- A third pair was strengthened by an identical URM infill and a thin reinforced mortar jacket on both sides of the infill Fig. (17).

- A fourth pair, in addition to the strengthening technique of the third pair, included transverse connection of the jacket reinforcement Fig. (17).

- Finally, the fifth pair, in addition to the strengthening technique of the second pair, included connection of the jacket reinforcement to the surrounding $\mathrm{R} / \mathrm{C}$ beams and columns through a steel plate anchored on the internal faces of the frame.

The main observational remarks on the behavior of repaired and strengthened bare and infilled frames are the following:

- The failure modes of the repaired bare frames were almost identical to those of the virgin ones. Again, plastic 


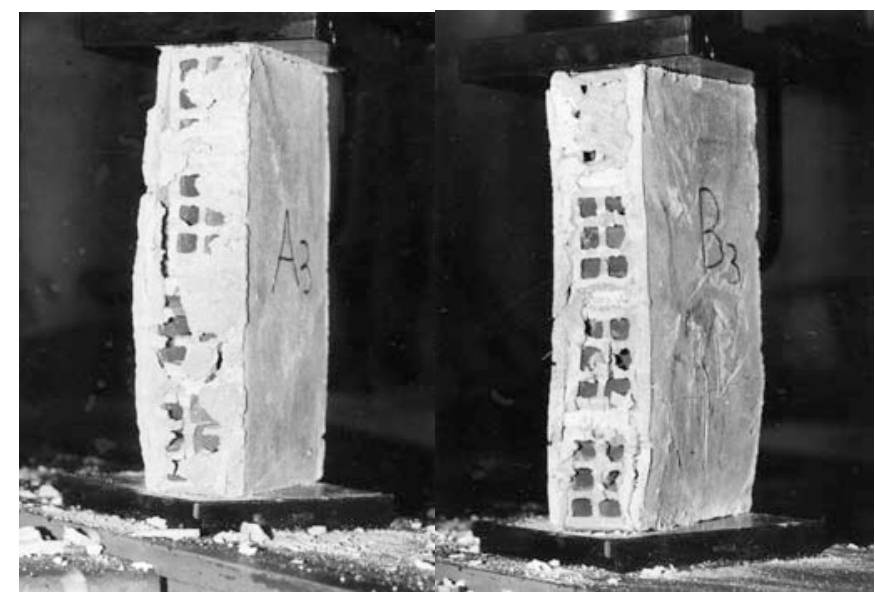

Fig. (16). Failure mode of a masonry wallet, strengthened by an $1 \mathrm{~cm}$ thick reinforced mortar jacket on both sides of the infill. The reinforcements of the two sides were not transversely connected to each other at specimen A3 and connected to each other at specimen B3.
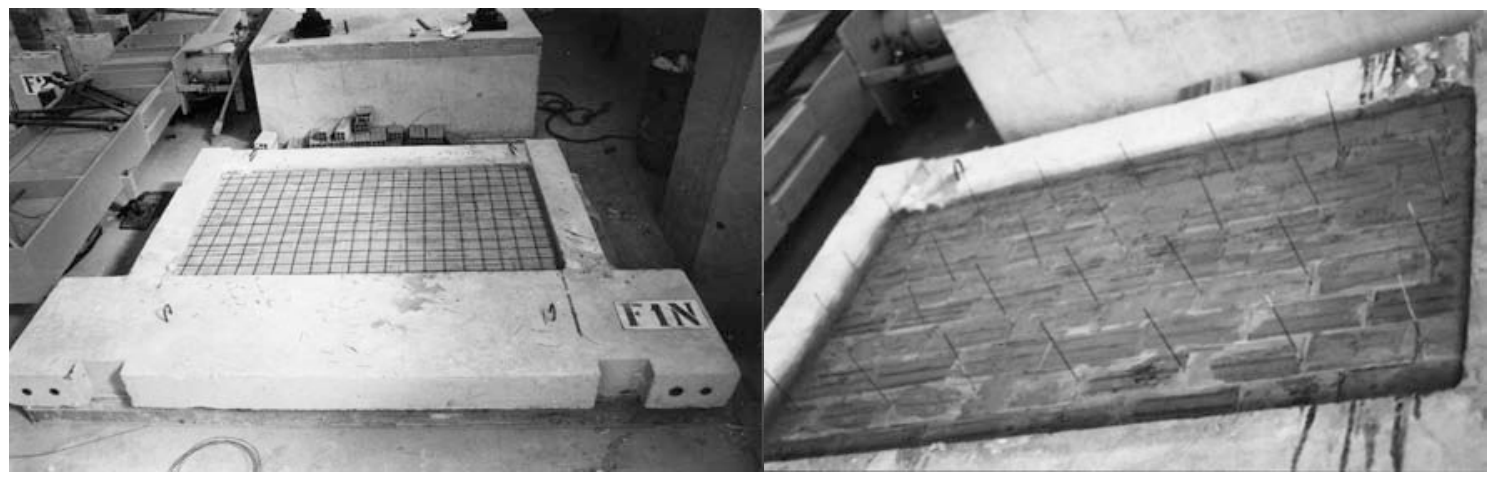

Fig. (17). Arrangement of the reinforcement of the mortar jacket and transverse reinforcement connecting both sides of the mortar jacket.

hinges occurred at the bottom and the top of the columns in the frame without axial force or at the bottom of the columns and the ends of the beam, in the frame with axial load. The only difference was that the hinges were formed at new cross sections, very close to the strengthened old ones Fig. (18).

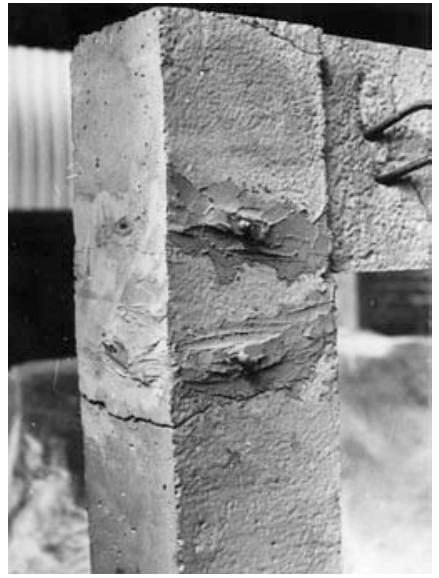

Fig. (18). Failure mode of the strengthened bare frame FBR.

- As it was expected, the failure modes of the frames F2R and F2NR, which were strengthened by the use of a typical new infill only, were also identical to the corresponding virgin frames of the first program Fig. (19).

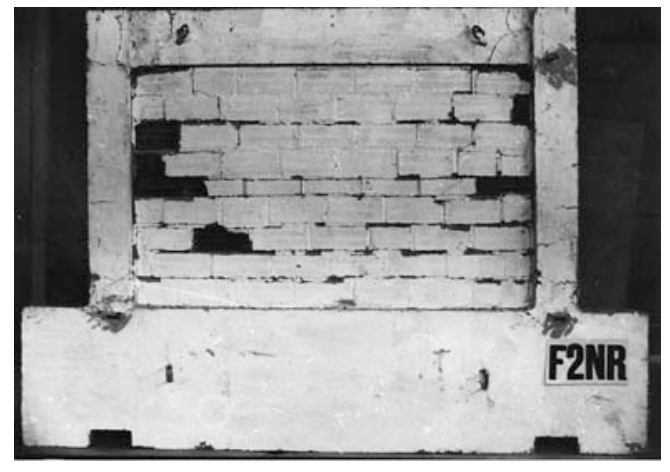

Fig. (19). Failure mode of the strengthened infilled frame F2NR.

- On the contrary, a new failure mode, completely different from the previous one, occurred in the case of the frames of the third pair with the thin reinforced mortar jacket on both sides of the infill. When the diagonal compressive strut begun to form after the separation of the infill from the surrounding frame, a compressive failure occurred at the corners of the infill due to splitting of the bricks, before the appearance of diagonal cracking of the infill. This behavior is in agreement with the remarks stated before, concerning the shear to compressive strength relation of the wallets. It seems that in the case of infills where the ratio of shear to compressive strength is relatively high, compressive failure might occur before diagonal cracking. As a result of the compressive failure of 
Table 6. Nomenclature of the Frame Models - Program \#3

\begin{tabular}{|c|c|c|c|c|c|c|c|}
\hline Name & $\begin{array}{l}\text { Repaired } R / C \\
\text { frame }\end{array}$ & $\begin{array}{l}\text { Addition of new } \\
\text { URM infill }\end{array}$ & $\begin{array}{l}1 \mathrm{~cm} \text { thick rein- } \\
\text { forced mortar on } \\
\text { both sides of the } \\
\text { infill }\end{array}$ & $\begin{array}{c}\text { Transverse } \\
\text { connection of the } \\
\text { jacket reinforcement }\end{array}$ & $\begin{array}{l}\text { Connection of the } \\
\text { reinforcement to the } \\
\text { surrounding } R / C \text { beams } \\
\text { and columns }\end{array}$ & \multicolumn{2}{|c|}{ Axial force } \\
\hline F2R & - & $\bullet$ & & & & - & \\
\hline F1R & - & • & • & & & • & \\
\hline F3R & - & - & - & & $\bullet$ & - & \\
\hline FBNR & $\bullet$ & \multicolumn{4}{|c|}{ Repaired bare frame } & & $\bullet$ \\
\hline F2NR & - & $\bullet$ & & & & & • \\
\hline F8NR & $\bullet$ & $\bullet$ & $\bullet$ & & & & $\bullet$ \\
\hline
\end{tabular}

the corners of the infill, the diagonal strut formed was not directed to the joint of the frame, but at the critical region of the columns, which suffered a brittle early shear failure (Fig. 20). For this reason the frame F1NR was abandoned and replaced by the frame F8NR, in which the corner bricks of the infill were replaced by local cast in place concrete. After this improvement, the frames overcome this problem and behave normally.

- In frames F4R and F4NR, which were strengthened furthermore by transverse connection of the jacket reinforcement, although some local compressive failures at the corners of the infill can be traced Figs. (21 and 22), finally the failure modes were almost typical. Note that in this case the shear to compressive strength ratio, although high, is lower than that of the previous one.

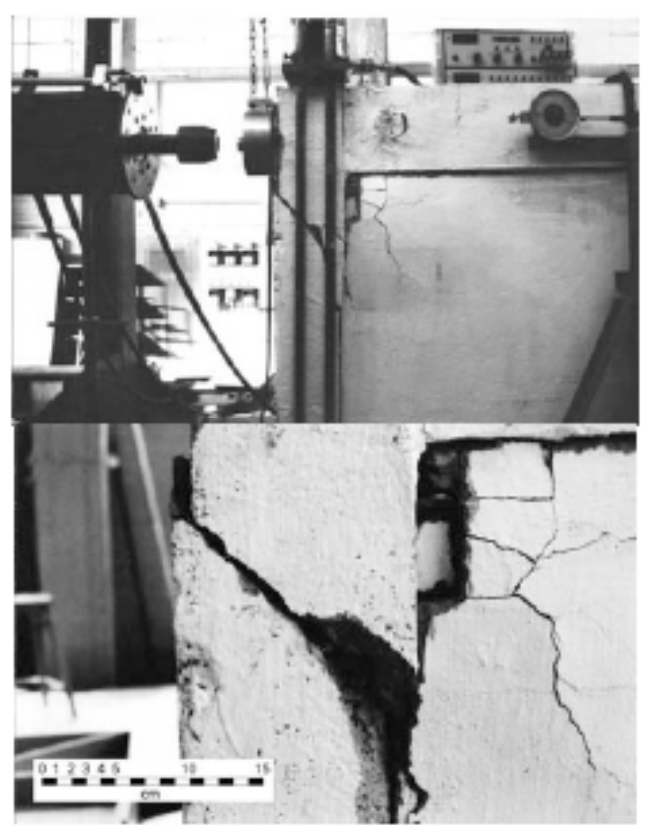

Fig. (20). Failure mode of the strengthened infilled frame F1NR.

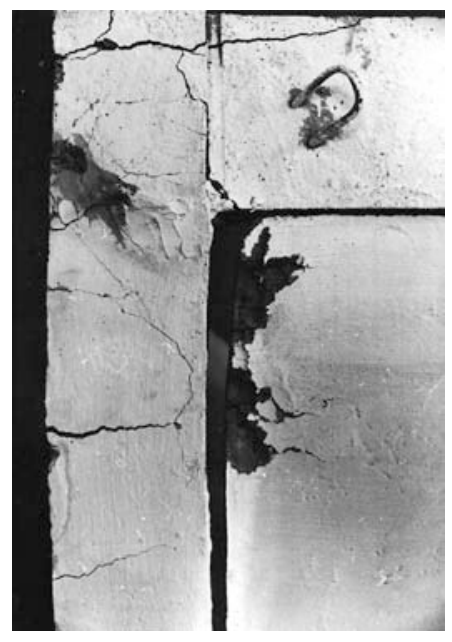

Fig. (21). Separation of the infill from the frame, local crashing of the infill corners of frame F4R.

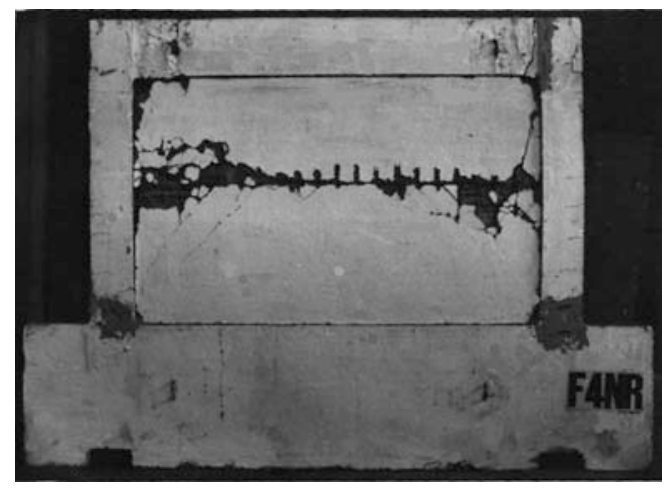

Fig. (22). Local crashing of the infill corners of frame F4NR, horizontal and diagonal cracking of the infill.

- Finally in frames F3R and F3NR, which were alternatively strengthened furthermore by the connection of the jacket reinforcement to the surrounding $\mathrm{R} / \mathrm{C}$ beams and columns, a similar failure mode with the previous one appeared again Figs. (23 and 24). 


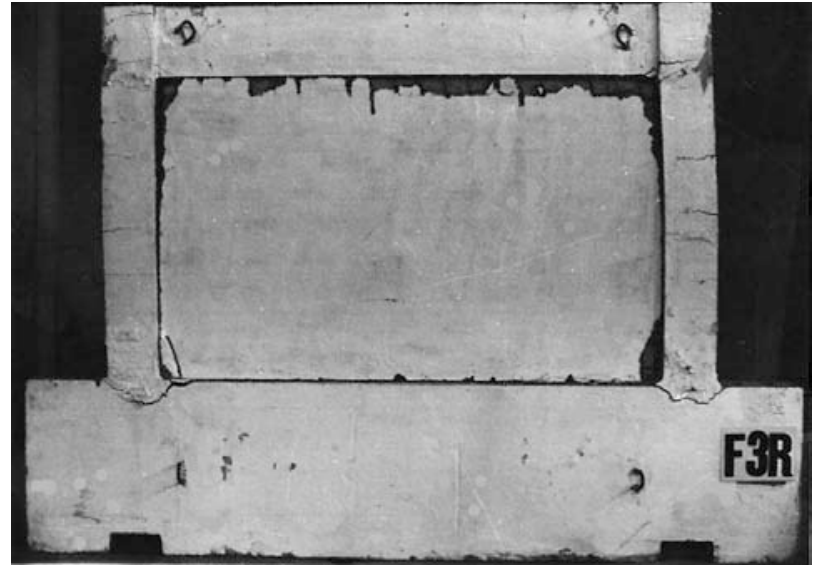

Fig. (23). Failure mode of the strengthened infilled frame F3R.

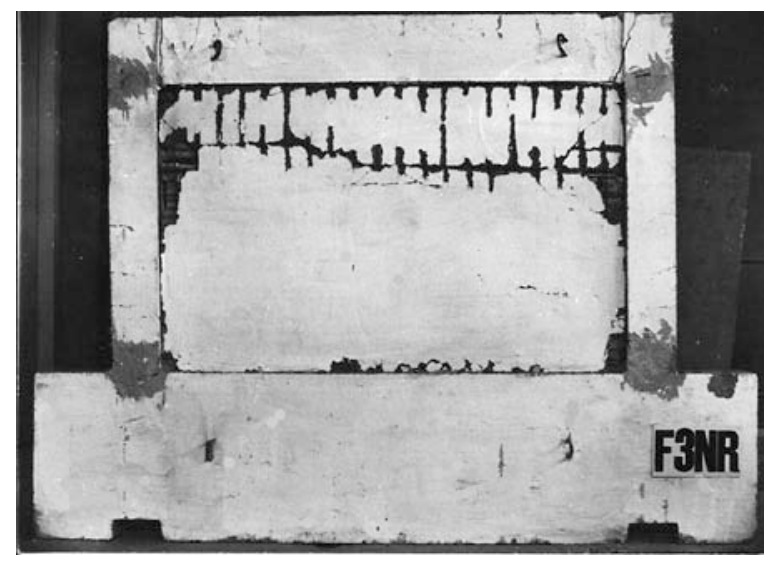

Fig. (24). Failure mode of the strengthened infilled frame F3NR.

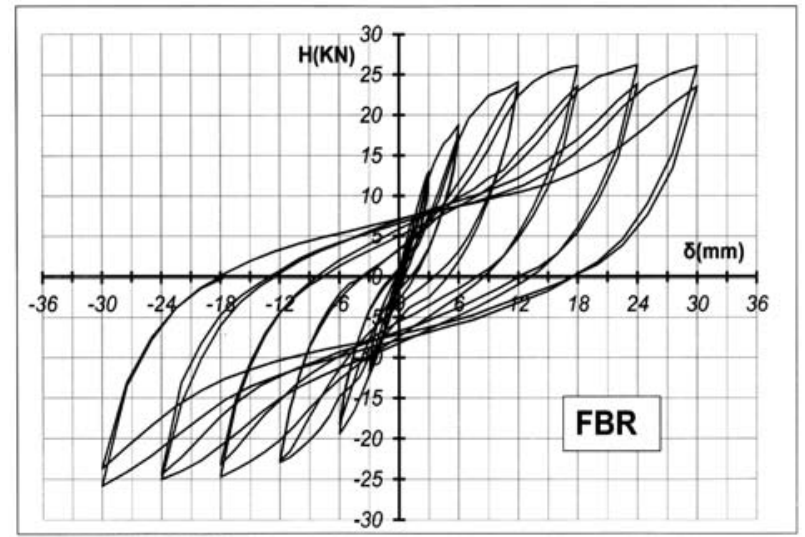

Fig. (25). Lateral load - displacement loops. Repaired bare frame FBR.

- The characteristics of the hysteretic loops of strengthened bare and infilled frames are almost the same. The loops of the bare frames are rich, typical to the inelastic rotation of the plastic hinges (Fig. 25). Again, pinching effects occur at the infilled frames, typical to brittle behavior due to infill cracking (Fig. 26). Pinching is more intense at the infilled frames with the mortar jacket (Fig. 27).

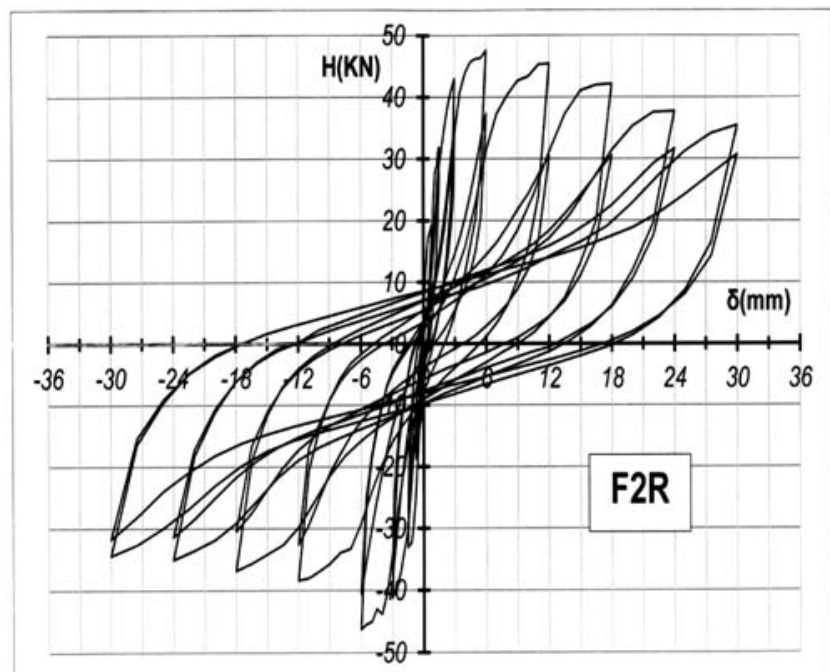

Fig. (26). Lateral load - displacement loops. Repaired infilled frame F2R.

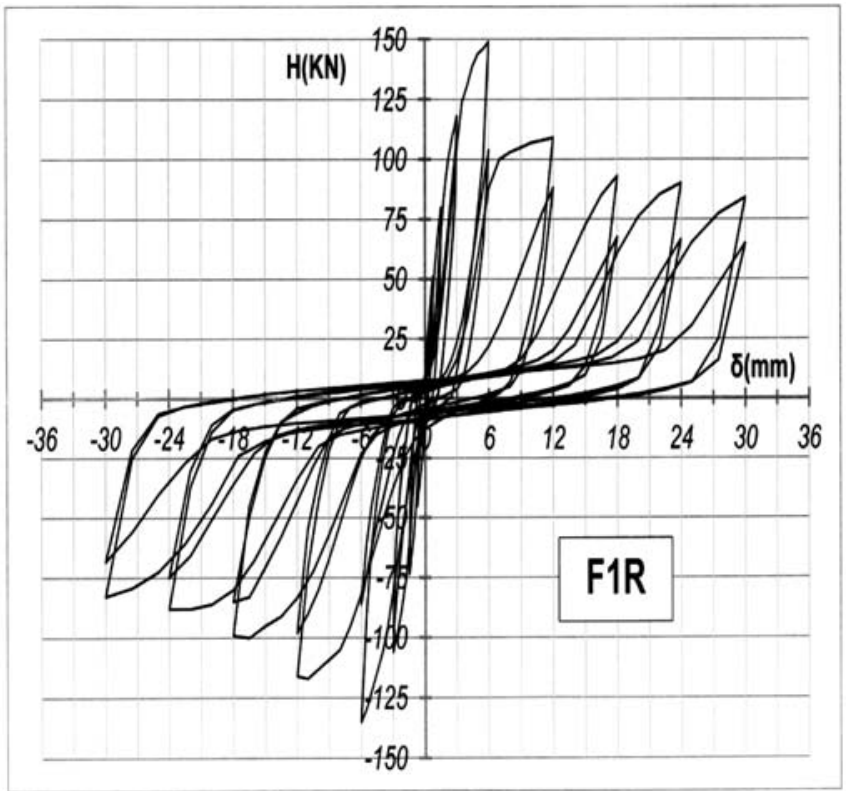

Fig. (27). Lateral load - displacement loops. Repaired infilled frame F1R.

\section{CONCLUSIONS}

\subsection{General conclusions from programs \#1 and \#2}

The main conclusions drawn from the results of programs \#1 and \#2 are the following:

- In case of relatively weak infills, as it was the rule of the examined infilled frames, the failure modes of the infilled frames are almost the same as those of the corresponding bare frames (Figs. 12, 13).

- The hysteretic loops of the bare frames are rich, typical to the inelastic rotation of the plastic hinges Figs. (9 and 14). On the contrary, pinching effects occur at the infilled frames, which are typical to brittle behavior due to infill cracking Figs. (10 and 15). 

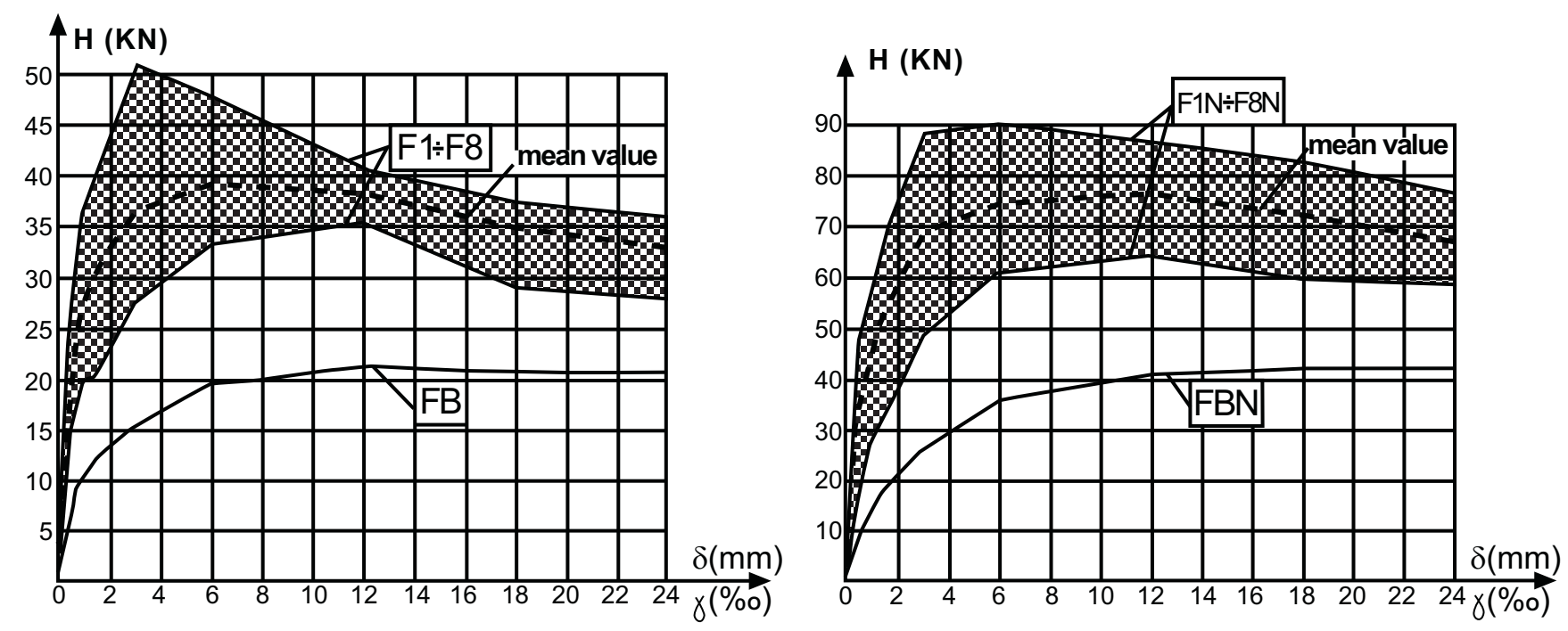

Fig. (28). Program \#1. Lateral load - displacement envelopes. Models without axial force (left), models with axial force (right). First cycles only.

- The load - displacement envelopes of the bare frames are that of an elastoplastic system without strain hardening Figs. (28 and 29). It can be noticed that at low angular distortions the curved branch of the envelope depicts the gradually increasing cracking of the frame. This curved branch is terminated at an angular distortion value of about 12 - $18 \%$ o where the frame reaches its maximum strength. From there on, the strength remains practically constant thanks to the ductile design of the frames.

- The presence of infills alters the load - displacement envelopes of the infilled frames Figs. (28 and 29). Note that the shaded region of Fig. (28) and the next figures represents the scatter of the values of the specimens stated. At the beginning, an almost linear behavior can be traced that depicts the composite action of the infilled frame. This linear behavior seems to be terminated when the angular distortion reaches values $0.2-0.5 \%$. From there on, an ascending curved branch appears, that depicts the separation of the infill from the surrounding frame and the cracking of both the frame and the infill. This ascending branch is terminated when the angular distortion reaches the value of $3-6 \%$. After that critical value of distortion is reached, a descending branch follows due to the loss of strength and integrity of the infill. This branch is almost linear and relatively smooth.

- It is apparent that in addition to the existing mechanism of energy dissipation by the rotation of the hinges of the bare frames, another mechanism appears in infilled frames. This is of friction type across the bounding frame and mainly across the cracks of the infill. It must be pointed out that this friction type mechanism is very active at low distortions, but it tends to disappear at high distortions since the infill degrades rapidly. This is why the maximum ratio in Figs. (30 and 31) occurs at low displacements, where infill offers much more than the $\mathrm{R} / \mathrm{C}$ frame. Design characteristics to ensure better con- finement of the infill to the frame can increase the effectiveness of the friction type mechanism at higher distortions.

- The infills offer strength, stiffness and energy dissipation capacity, depending on the strength of the infill in relation to the strength of the frame.

- Table 8, based on the values presented in Table 7, describes the influence of the parameters investigated on the initial stiffness of program \#1. For example, the first value of the table is the ratio of the sum of four values of initial stiffness ratios of Table 7, corresponding to specimens F1, F2, F3, F4 which are considered to have good contact conditions, to the sum of the four values corresponding to specimens F5, F6, F7, F8 which are considered to have bad contact conditions. It is obvious that initial stiffness is much more influenced by the contact conditions, especially in the presence of axial force. Better mortar quality plays a limited role in stiffness increase, while the existence of a lintel beam plays a rather negative role, probably because of premature sliding between the lintel beam and the neighboring bricks that appears at low distortions.

- Table 10, based on the values of Table 9, describes the influence of the parameters investigated at program \#2. In the case that the aspect ratio is 1.5 , the length of the infill is $50 \%$ greater than in the case of aspect ratio 1.0. This difference is depicted on the initial stiffness, which is much greater in the first case. The other two parameters do not seem to have significant influence. The stiffness increase of the infilled frames in respect to the corresponding bare frames is of the same order of magnitude, as in program \#1 (4-5 times). The ratio of the initial stiffness of the infilled frames to the initial stiffness of the bare frames, measured at very low distortions of $0.1 \%$, is about $4.2-5.3$ (Tables 7 and 9). 
Table 7. Ratio of Infilled Frames to Bare Frames Initial Stiffness - Program \#1 (Stiffness Calculated at Low Distortion 0.1\%)

\begin{tabular}{|c|c|c|c|c|c|}
\hline Frames & Axial Force & Initial Stiffness Ratio & Frames & Axial Force & Initial Stiffness Ratio \\
\hline F2 & \multirow{6}{*}{ no } & 4.78 & $\mathrm{~F} 2 \mathrm{~N}$ & \multirow{6}{*}{ yes } & 6.26 \\
\hline F3 & & 4.75 & $\mathrm{~F} 3 \mathrm{~N}$ & & 6.38 \\
\hline $\mathrm{F} 4$ & & 4.96 & $\mathrm{~F} 4 \mathrm{~N}$ & & 6.02 \\
\hline F5 & & 5.05 & F5N & & 4.37 \\
\hline F7 & & 3.55 & F7N & & 4.01 \\
\hline F8 & & 4.24 & F8N & & 4.27 \\
\hline \multicolumn{2}{|c|}{ Average } & 4.5 & \multicolumn{2}{|c|}{ Average } & 5.3 \\
\hline
\end{tabular}

Table 8. Influence of the Parameters Investigated in Program \#1 on the Initial Stiffness. Ratio of Initial Stiffness - Program \#1 (Stiffness Calculated at Low Distortion $0.1 \%$ )

\begin{tabular}{|c|c|c|c|c|c|}
\hline \multicolumn{2}{|c|}{ Contact: Good/Bed } & \multicolumn{2}{|c|}{ Mortar Type: S/O } & \multicolumn{2}{|c|}{ Lintel Beam: YES/NO } \\
\hline \multicolumn{2}{|c|}{ Axial Force } & \multicolumn{2}{|c|}{ Axial Force } & \multicolumn{2}{|c|}{ Axial Force } \\
\hline no & yes & no & yes & no & yes \\
\hline 1.16 & 1.59 & 1.02 & 1.10 & 0.95 & 0.93 \\
\hline
\end{tabular}

Table 9. Ratio of Infilled Frames to Bare Frames Initial Stiffness - Program \#2 (Stiffness Calculated at Low Distortion 0.1\%)

\begin{tabular}{|c|c|c|c|c|c|}
\hline Frames & Axial Force & Initial Stiffness Ratio & Frames & Axial Force & Initial Stiffness Ratio \\
\hline $\mathrm{F}_{1,1,9}$ & \multirow{5}{*}{ no } & 2.2 & $\mathrm{FN}_{1,1,9}$ & \multirow{5}{*}{ yes } & 3.8 \\
\hline $\mathrm{F}_{1,2,6}$ & & 3.2 & $\mathrm{FN}_{1,2,6}$ & & 3.2 \\
\hline $\mathrm{F}_{1,2,9}$ & & 4.0 & $\mathrm{FN}_{1,2,9}$ & & 4.7 \\
\hline $\mathrm{F}_{1.5,2,6}$ & & 4.2 & $\mathrm{FN}_{1.5,2,6}$ & & 5.9 \\
\hline $\mathrm{F}_{1.5,2,9}$ & & 4.3 & $\mathrm{FN}_{1.5,2,9}$ & & 6.4 \\
\hline \multicolumn{2}{|c|}{ Average } & 4.2 & \multicolumn{2}{|c|}{ Average } & 5.2 \\
\hline
\end{tabular}

Table 10. Influence of the parameters investigated in program \#2 on the initial stiffness. Ratio of initial stiffness - program \#2 (stiffness calculated at low distortion $0.1 \%$ )

\begin{tabular}{|c|c|c|c|c|c|}
\hline \multicolumn{2}{|c|}{ Aspect ratio: 1.5/1.0 } & Reinforcement ratio 1.8/1.0 & \multicolumn{2}{c|}{ Anfill thickness: 9.0/6.3 } \\
\hline \multicolumn{2}{|c|}{ Axial force } & Axial force & no & no & yes \\
\hline no & yes & 0.88 & 0.94 & 0.90 & 1.08 \\
\hline
\end{tabular}

- The increase in strength is maximized at low displacements, where the infill contributes with its full strength, while the frame has not reached its maximum strength yet. For higher values of displacements the contribution of the infill diminishes. Higher values of the strength ratio of the infilled frames over the bare frames correspond to stronger infills in relation to the frame. As a general conclusion, the overall behavior of the structural system, composed of a brittle and a ductile member, is governed by the behavior of the brittle member at low displacements and by the behavior of the ductile member when the distortions are high. The ratio of the strength of the infilled frames to the strength of the bare frames is about $2.5-3.0$ at distortions of $2 \%$. At higher displacements the infill gradually degrades but it still offers to the 
strength of the system. The ratio is about $1.5-1.7$ at distortions of 30\%o Figs. (30 and 31).
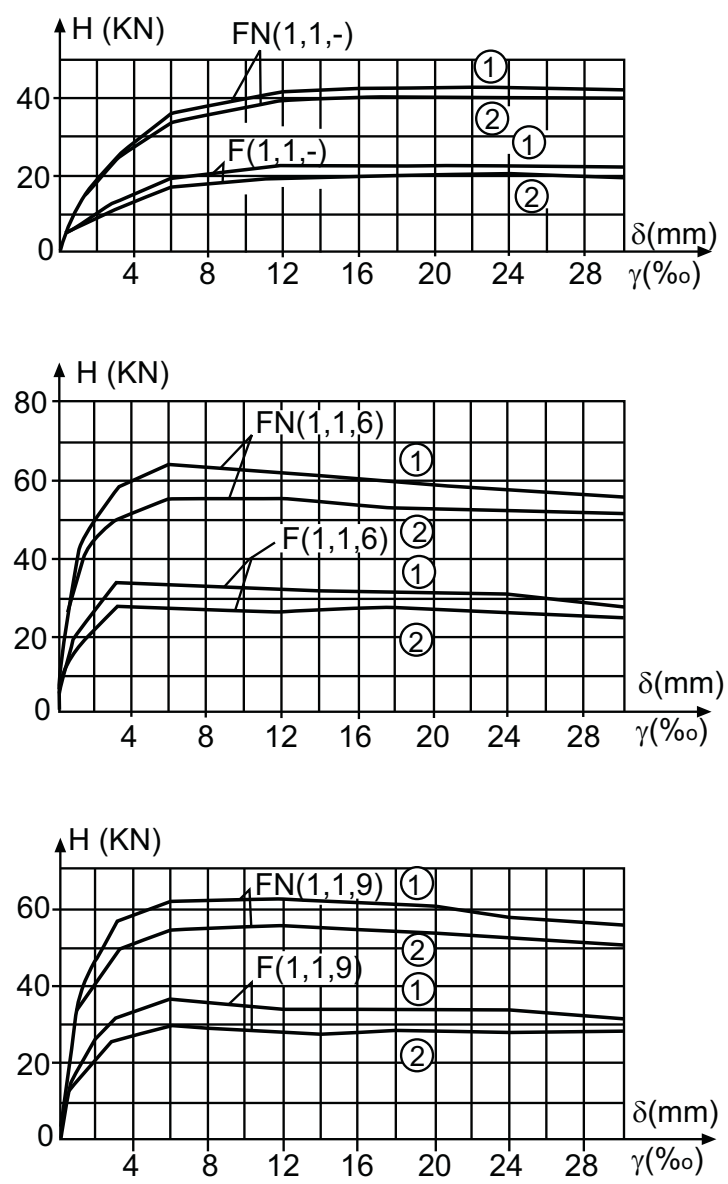

Fig. (29). Program \#2. Lateral load - displacement envelopes of bare frames $F_{1,1,-}$ and $F_{1,1,-}$, infilled frames $F_{1,1,6}$ and $F_{1,1,6}$ and infilled frames $\mathrm{F}_{1,1,9}$ and $\mathrm{FN}_{1,1,9}$.

- The maximum ratio of the energy dissipation capacity of the infilled frames to corresponding bare frames, as calculated according to Fig. (32). occurs again at low displacements where the system dissipates energy through friction across the relatively small width infill cracks. It

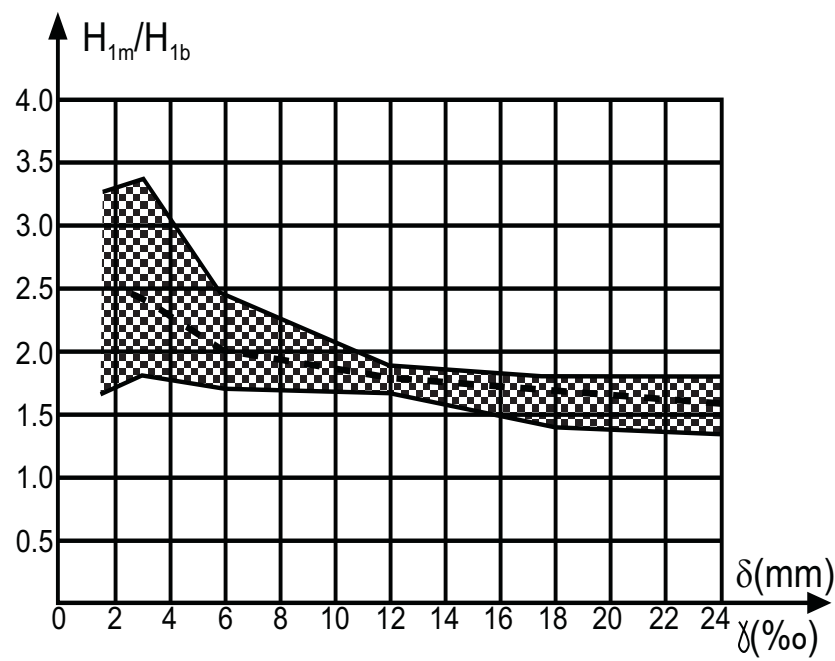

must be pointed out that higher values of the dissipation ratio appear in the case of strong frames, i.e. when there is an external axial compression load on the columns or an increased reinforcement ratio. This result can be attributed to the fact that when the frame is stronger the confinement of the infill is better. The ratio of the energy dissipation capacity of the infilled frames to the energy dissipation capacity of the bare frames is about 3.0-5.0 at distortions of $2 \%$ and about $1.3-1.5$ at distortions of 30\%o Figs. (33 and 34).

Models without axial force (left), models with axial force (right). First cycles only.

- Ductility of the infilled frames is satisfactory, though lower than that of the bare frames Fig. (35) and Tables 11 and $\mathbf{1 2 .}$

- Degradation due to cycling causes $7-9 \%$ loss of strength in bare frames during the second cycle in relation to the strength of the first cycle. The corresponding loss in infilled frames is up to $17 \%$. It is worth mentioning that this maximum loss appears to distortions equal to $3-12 \%$, which is the range of maximum contribution of the infill Fig. (36).

- Loss of energy dissipation during the second cycle in relation to the energy dissipation during the first cycle is by far greater than the corresponding loss of strength of both the bare and the infilled frames. Maximum loss is about $35 \%$ in bare frames and about $50 \%$ in infilled frames. The maximum loss also appears in the range of distortions equal to $3-12 \%$ Fig. (37).

\subsection{The Influence of the Parameters Investigated in Pro- grams \#1 and \#2}

The parameters investigated in programs \#1 and \#2 have the following influence on the results:

- The axial load on the columns almost doubles strength in both the bare and infilled frames Fig. (28). In the case of bare frames this is reasonably attributed to the contribution of the axial load on the strength of the critical sections of the columns. In the case of infilled frames the somehow surprising result that, beyond the doubling of

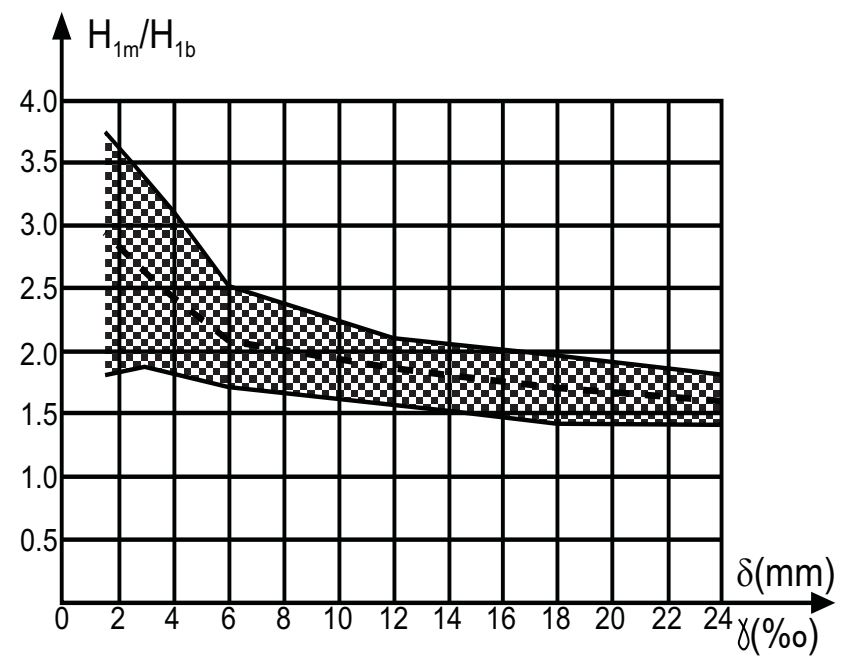

Fig. (30). Program \#1. Ratio of infilled frames to bare frames strength. 


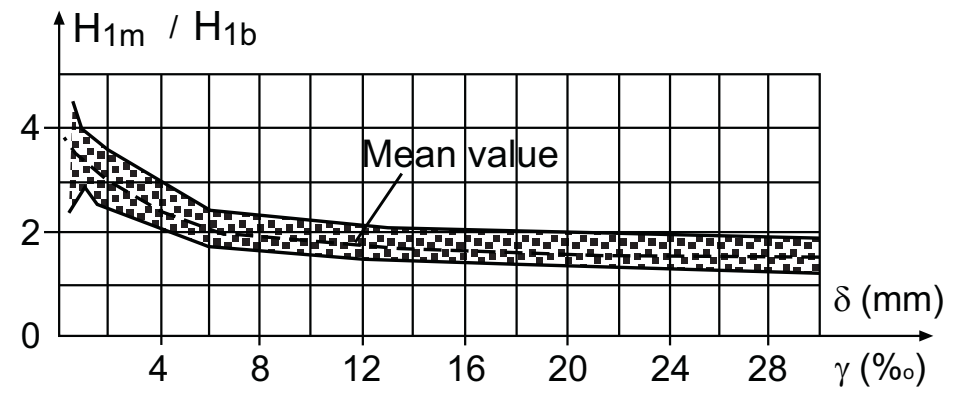

Fig. (31). Program \#2. Mean value and scatter of the ratio of infilled frames to bare frames strength $\mathrm{H}_{1 \mathrm{~m}} / \mathrm{H}_{1 \mathrm{~b}}$.
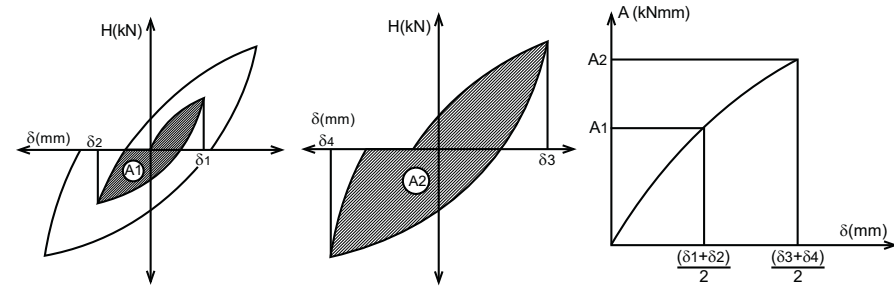

Fig. (32). Calculation of energy dissipation per cycle. Typical diagram of energy dissipation versus displacement.
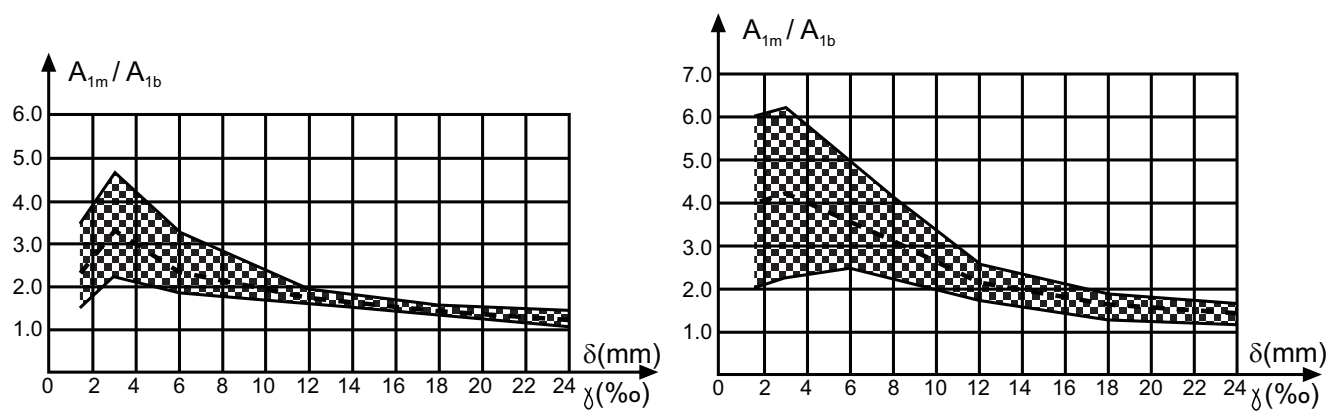

Fig. (33). Program \#1. Ratio of infilled frames to bare frames energy dissipation. Models without axial force (left), models with axial force (right). First cycles only.

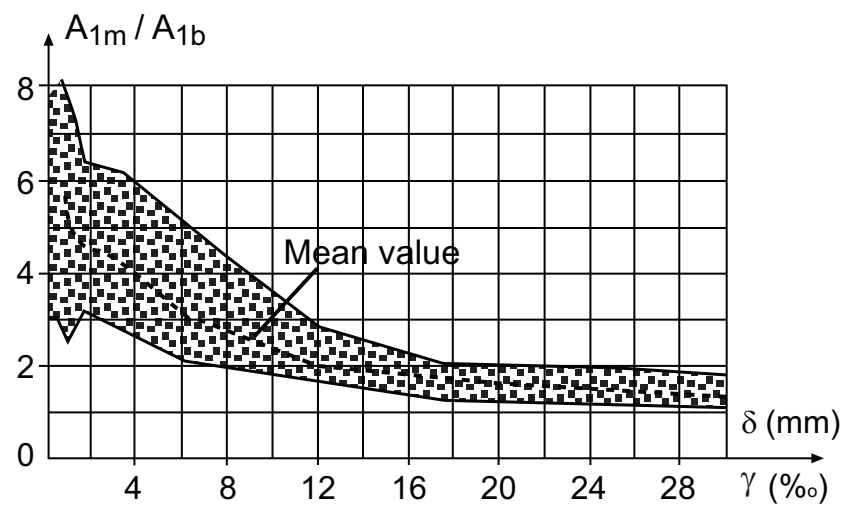

Fig. (34). Program \#2. Mean value and scatter of the ratio of infilled frames to bare frames energy dissipation $A_{1 \mathrm{~m}} / A_{1 b}$.

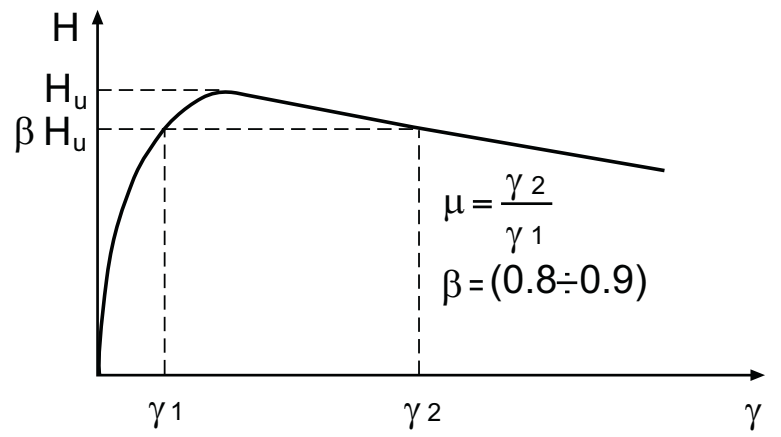

Fig. (35). Definition of the ductility index. 
Table 11. Ductility Index of Infilled Frames - Program \#1

\begin{tabular}{|c|c|c|c|c|c|}
\hline \multirow{2}{*}{ Frames } & \multirow{2}{*}{ Axial Force } & \multicolumn{2}{|c|}{ At 0.9Hu } & \multicolumn{2}{|c|}{ At 0.8Hu } \\
\cline { 2 - 5 } & & Scatter & Average & $5.7-33.2$ & 14.9 \\
\hline \hline F1-F8 & no & $2.8-15.4$ & 6.1 & $5.4-29.1$ & 13.9 \\
\hline F1N-F8N & yes & $2.6-9.0$ & 4.9 & \\
\hline
\end{tabular}

Table 12. Ductility Index of Infilled Frames - Program \#2

\begin{tabular}{|c|c|c|c|c|c|}
\hline \multirow{2}{*}{ Frames } & \multirow{2}{*}{ Axial Force } & \multicolumn{2}{|c|}{ At 0.9Hu } & \multicolumn{2}{|c|}{ At 0.8Hu } \\
\cline { 2 - 6 } & & Scatter & Average & $8.4-20.8$ & 12.3 \\
\hline \hline F1 - F8 & no & $3.4-8.3$ & 5.4 & $10.3-19.5$ & 14.3 \\
\hline F1N - F8N & yes & $5.0-8.6$ & 7.0 & \\
\hline
\end{tabular}

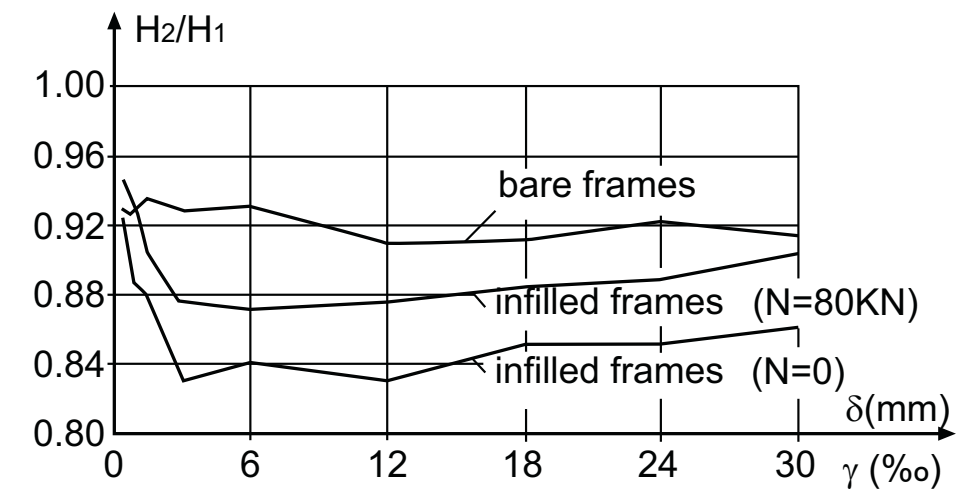

Fig. (36). Program \#2. Ratio of strength $\mathrm{H}_{2} / \mathrm{H}_{1}$ of the second cycle over the strength of the first cycle of imposed displacements (mean values).

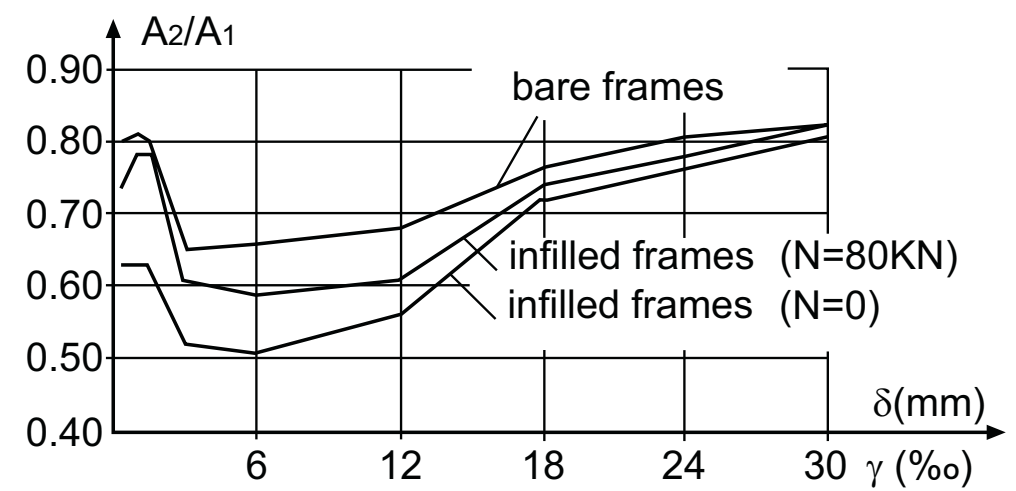

Fig. (37). Program \#2. Ratio of the energy dissipated $A_{2} / A_{1}$ during the second cycle over the energy dissipated during the first cycle of imposed displacements (mean values).

the contribution of the columns, the infill also doubles its contribution, is possibly attributed to the confinement offered by the axial force to the infill. In the presence of axial load, initial stiffness Tables 7 and 9 slightly increases and energy dissipation capacity is almost double, as in the case of strength increase.

- Good contact conditions increase strength, initial stiffness Table $\mathbf{8}$ and energy dissipation capacity. The increases are significant at low level of displacement and tend to zero at displacements higher to the critical. This is attributed to the fact that, even in the case of initial good contact, the infill gradually loses its contacts to the surrounding frame after critical displacement. Ductility is not significantly affected.

- The use of strong mortar leads to a slight increase in strength, initial stiffness Table $\mathbf{8}$ and energy dissipation capacity, while ductility is not affected. This is attributed to the fact that even over doubling the strength of the 
mortar, the increase of shear strength is not significant, about $25 \%$ Table 2 , so the increase of the strength of the system is much less.

- The presence of a concrete lintel beam decreases strength, initial stiffness and energy dissipation capacity at low levels and increases them at high levels of displacement. Ductility is not affected either. The decrease is attributed to premature sliding across the mortar joints between the lintel beam and the neighboring series of bricks at low levels and the increase is attributed to the stabilizing role of the lintel beam at high levels of displacement. This failure mode of the infill leads to the formation of two pairs of diagonal struts, instead of the one pair usually expected. These struts extend from the corners to the opposite column midheight and in turn lead to the formation of plastic hinges at their ends on the columns midheight. As a result, diagonal cracking of the columns occur, due to their low slenderness ratio.

- As it is expected, the aspect ratio of the frame does not have any influence on the strength of the bare frames. On the contrary, the length of the infill of the infilled frames with an aspect ratio equal to 1.5 is about $50 \%$ greater compared to the infill of the infilled frames with an aspect ratio equal to 1.0. This infill length increases its contribution to the system. As a result, infilled frames with an aspect ratio equal to 1.5 present increased strength of about $30 \%$, increased initial stiffness of about $60 \%$ Table $\mathbf{1 0}$ and energy dissipation capacity of about $30 \%$.

- The increased reinforcement ratio of the columns and beam increases strength, initial stiffness and energy dissipation capacity of bare and infilled frames. The increase of strength and energy dissipation capacity is about $30 \%$ at bare frames and $20 \%$ at infilled frames. It must be noticed that, as it is expected, in the case of increased reinforcement ratio, the increase of the stiffness of the infilled frames in relation to the corresponding bare frames is lower than the increase in the case of low reinforcement ratio Table $\mathbf{8}$.

- The increased thickness of the masonry slightly increases strength, initial stiffness and energy dissipation capacity of the infilled frames. This increase is surprisingly very small, in the order of magnitude of $5 \%$. Note that an increase that is proportional to the thickness should result in $43 \%$ increased strength of the infill, and a corresponding lower increase of the infilled frame.

\subsection{Conclusions from Program \#3}

The main conclusions drawn from the results of the program \#3 are the following:

- In case of stronger infills, especially when the shear to compressive strength ratio is high, exceeding the value of about 0.4 , some undesirable failure modes may occur, that lead to brittle failure of columns.

- Repaired bare frames FBR and FBNR and infilled frames F2R and F2NR show lower initial strength compared to the virgin ones of the first program, probably because some cracks were not repaired by epoxy resins Fig. (38).

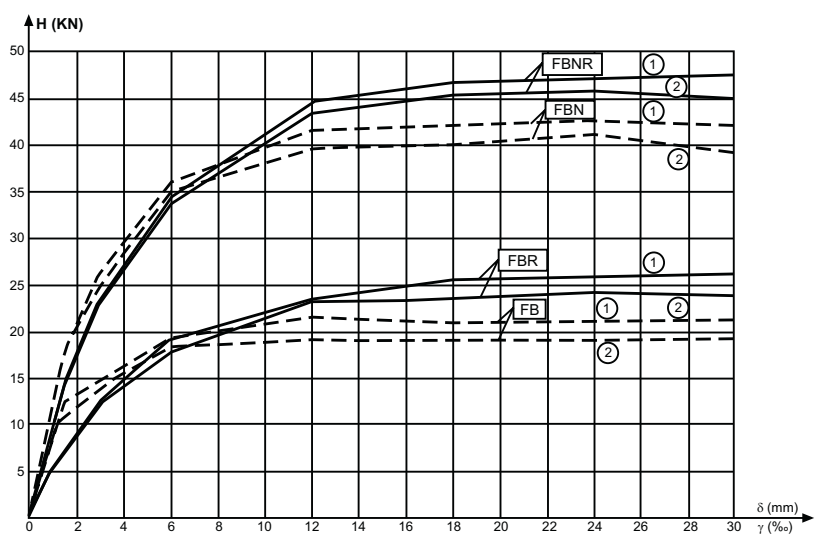

Fig. (38). Lateral load - displacement envelopes of repaired versus virgin bare frames.

- Infilled frames strengthened by mortar jackets, show higher initial stiffness. It seems that the transverse reinforcement and the connection to the frame do not alter much the initial stiffness Fig. (39).

- Repaired bare frames FBR and FBNR at low displacements show lower strength compared to the virgin ones of the first program, attributed again to the fact that probably some cracks were not repaired by epoxy resins. On the contrary, at high displacements, the strength of the repaired frames is greater than that of the virgin ones because the plastic hinges were formed in such a way that the distance of the hinges on the column is lower than that of the virgin frame Fig. (38).

- The strength of the infilled frames F2R and F2NR, strengthened only by a typical URM infill, is almost the same with the strength of the virgin ones.

- The frames with the mortar jacket are much stronger. It seems that the mortar jacket offered much more than the brick infill itself. The transverse reinforcement and the reinforcement connection to the frame added some more strength, especially in the case of the presence of axial load. The contribution of the infills is again maximized at low displacements. For higher values of displacements the contribution of the infill diminishes but it is still considerable Fig. (39).

- The energy dissipation capacity of the infilled frames, as calculated according to Fig. (32) and normalized to the displacement level is again much greater than that of the bare frames Fig. (40). It must be pointed out that higher values of dissipation appear in the case of strong frames, i.e. when there is an external axial compression load on the columns and mortar jackets at the infill. It seems that the transverse reinforcement and the connection to the frame do not offer much.

\subsection{General Remarks}

- Although 2D experiments like the ones described in this paper can be organized in a way to prevent out of plain failure of the infills, this danger is always present in real structures. Starting at relatively low displacements, a separation of the infills from the surrounding frame at the non-loaded corners was obvious during the experiments. Low cost strengthening methods can easily anticipate connection of the infills to the surrounding frame. Al- 

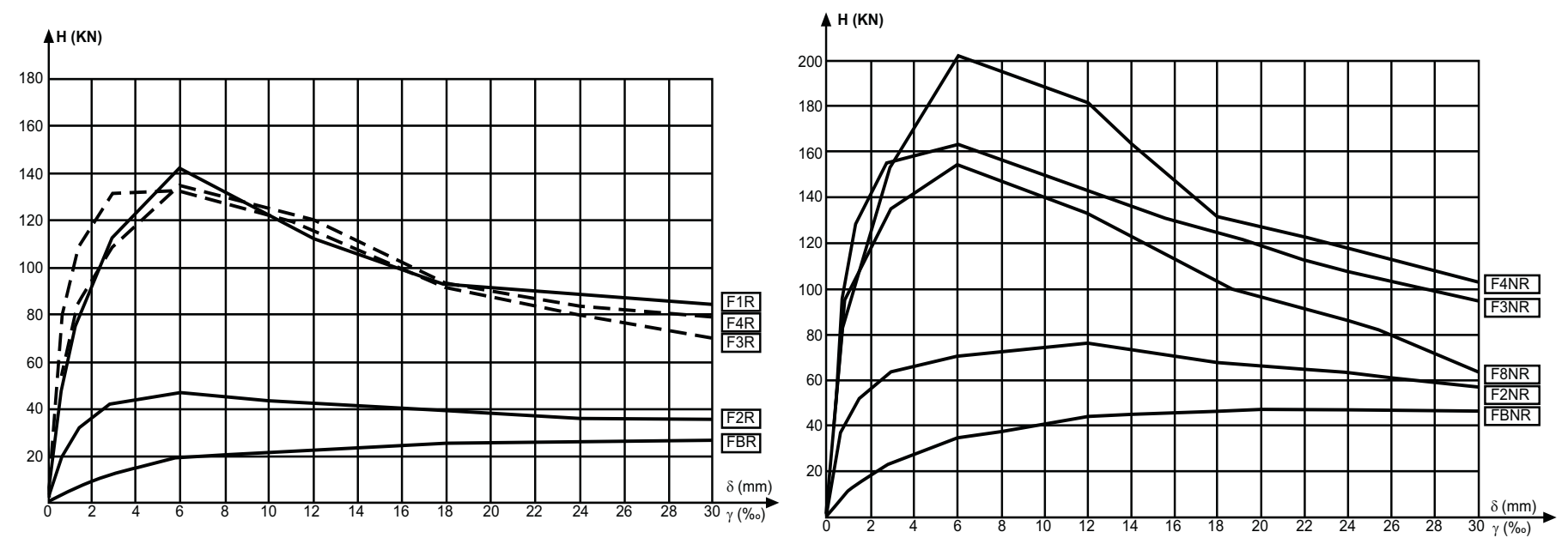

Fig. (39). Lateral load - displacement envelopes of repaired bare and infilled frames without and with axial load.
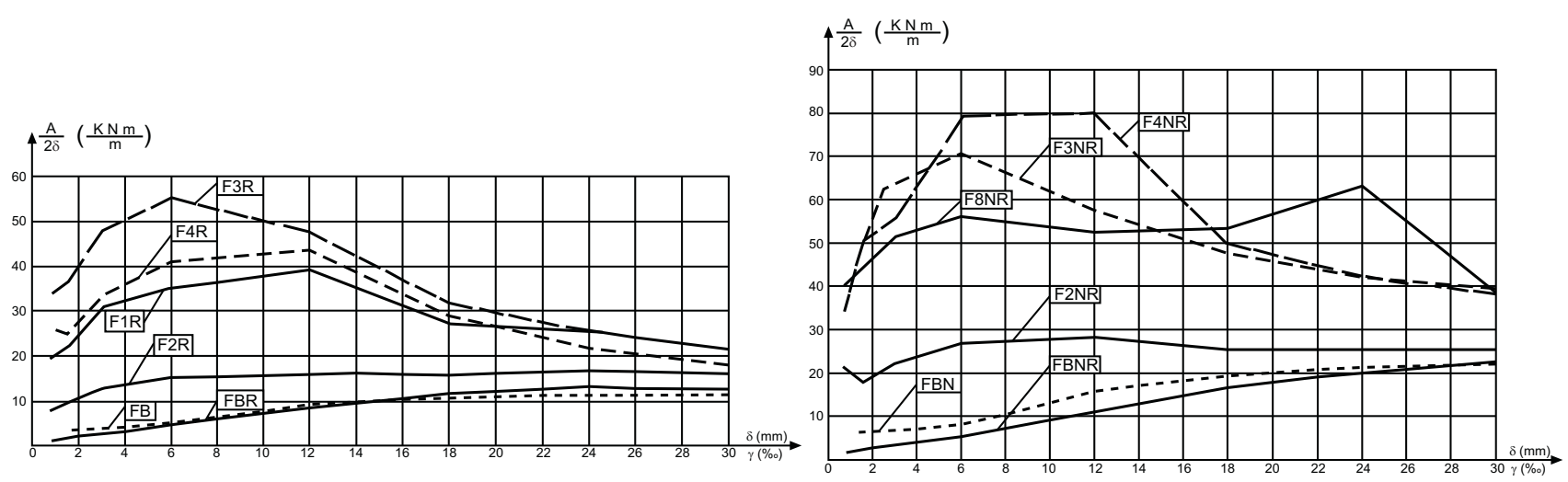

Fig. (40). Normalized energy dissipation - displacement envelopes of repaired bare and infilled frames without and with axial load.

though these connections do not offer to the strength, they can prevent the out of plain failure of the system.

- Simple infilling techniques, like the construction of a brick wall, with a width equal to half the width of the adjacent columns, can double the strength of the system and triple the energy dissipation capacity. Further measures, like the application of reinforced mortar jackets $3 \mathrm{~cm}$ thick in both sides of the brick wall, can further triple the strength and the energy dissipation capacity. In the case of the later intense intervention, a connection to the surrounding frame should be anticipated.

- From the review of the literature and the experimental results of the present programs it can be concluded that there is a need for an analytical model to describe the cyclic behavior of the infill that will be capable to comply with existing inelastic analysis computer programs. This model has to take into account the parameters which are known to affect the behavior of the infill. Although these parameters are expected to be very many, appropriately oriented experimental and analytical efforts can give an acceptable result, at least for the usual infills. In this direction, based on the results of the first and second experimental programs, an analytical model has been proposed to describe the behavior of relatively weak brick masonry infills [17]. This model, after adaptation, has already been successfully used in several applications [18, 19].

\section{CONFLICT OF INTEREST}

The author confirm that this article content has no conflicts of interest.

\section{ACKNOWLEDGEMENT}

Declared none.

\section{REFERENCES}

[1] E. Vintzeleou, "Behaviour of Infilled Frames Subject to Lateral Actions", A State-of-the-Art Report, EC8 Editing Panel, Brussels, 1987.

[2] CEB, Seismic Design of Concrete Structures, Second Draft, CEB B.I. N. 149, March 1982.

[3] M.J.N. Priestley, "Masonry Structural Systems for Region of High Seismicity", In: Proceedings of $7^{\text {th }}$ W.C.E.E., Istanbul, vol. 4, 1980, pp. 441-448.

[4] V.V. Bertero, and S. Broken, "Infills in seismic resistant buildings", J. Struct. Div. ASCE, vol. 109, no. 6, pp. 1337-1361, 1983.

[5] Eurocode 8: Design of structures for earthquake resistance - Part 1: General rules, seismic actions and rules for buildings, EN 19981, CEN, Brussels, 2004.

[6] J.W. Axley, and V.V. Bertero, "Infill Panels: Their Influence on Seismic Response of Buildings", EERC Report N. 79-28, Univ. of California, 1979.

[7] S. Sugano, and M. Fujimura, "Aseismic Strengthening of Existing Reinforced Concrete Buildings" In: Proceedings of the $7^{\text {th }}$ WCEE, Istanbul, 1980. 
[8] F. Pires, A. Campos-Costa, and S. Raposo, "Hysteretic Behavior of RC Frames Infilled with Brick Masonry Walls", In: Proceedings of the $10^{\text {th }}$ ECEE, Vienna, 1994.

[9] G. Manos, M. Triamatakis, and B. Yasin, "Experimental and Numerical Simulation of the Influence of Masonry Infills on the Seismic Response of RC Framed Structures", In: Proceedings of the $10^{\text {th }}$ ECEE, Vienna, 1994

[10] F. M. Mazzolani, G.D. Corte, L. Fiorino, and E. Barecchia, "Fullscale Cyclic Tests of a Real Masonry-Infilled RC Building for Seismic Upgrading", COST Workshop, Prague, 2007.

[11] K.C. Stylianidis, "Experimental Investigation of the Behaviour of Single-Story Infilled R/C Frames under Cyclic Quasi-Static Horizontal Loading - Parametric Analysis", Ph. D. thesis (in Greek), Aristotle University of Thessaloniki, Thessaloniki, Greece 1985.

[12] T.N. Valiasis, "Experimental Investigation of the Behaviour of $R / C$ Frames Filled with Masonry Panels and Subjected Cyclic Horizontal Load - Analytical Modelling of the Masonry Panel", Ph. D. thesis (in Greek), Aristotle University of Thessaloniki, Thessaloniki Greece, 1989.

[13] D.D. Sarigiannis, "Experimental Investigation on the Behaviour of $R / C$ Infilled Frames, Repaired with Various Infill Techniques, un- der Cyclic Horizontal Loading", Ph. D. thesis (in Greek), Aristotle University of Thessaloniki, Thessaloniki, Greece 1989.

[14] K.C. Stylianidis, "Cyclic behaviour of Infilled R/C/ Frames" In: Proceedings of $8^{\text {th }}$ I.B.B.M.C., Dublin, vol. 2, 1988, pp. 792-799.

[15] T.N. Valiasis, and K.C. Stylianidis, "Masonry Infilled R/C/ Frames under Horizontal Loading Experimental Results", Eur. Earthquake Eng., vol. 3, pp. 10-20, 1989.

[16] R. Zarnic, and M. Tomazevic, "The Behaviour of Masonry Infilled Reinforced Concrete Frames Subjected to Cyclic Lateral Loading", In: Proceedings of $8^{\text {th }}$ W.C.E.E., San Francisco, vol. 6, 1984, pp. 863-870.

[17] T.N. Valiasis, K.C. Stylianidis, and G.G. Penelis, "Hysteresis model for weak brick masonry infills in R/C frames under lateral reversals", Eur. Earthquake Eng., vol. 1, pp. 3-9, 1993.

[18] A.J. Kappos, K.C. Stylianidis, and C.N. Michailidis, "analytical models for brick masonry infilled $\mathrm{R} / \mathrm{C}$ frames under lateral loading", J Earthquake Eng., vol. 2, no. 1, pp. 59-87, 1998.

[19] C.N. Michailidis, K.C. Stylianidis, and A.J. Kappos, "Analytical Modelling of Masonry Infilled R/C Frames Subjected to Seismic Loading" In Proceedings of the $10^{\text {th }}$ ECEE, Vienna, 1994, vol. III, pp. 1519-1524.

(c) K.C. Stylianidis; Licensee Bentham Open.

This is an open access article licensed under the terms of the Creative Commons Attribution Non-Commercial License (http://creativecommons.org/licenses/by-nc/3.0/) which permits unrestricted, non-commercial use, distribution and reproduction in any medium, provided the work is properly cited. 